\title{
THE SWAMI INSPECTION ROBOT: FERNALD SITE REQUIREMENTS
}

by

\section{F. Brack Hazen}

\author{
FERMCO \\ Fernald Environmental Restoration \\ Management Corporation \\ Fernald Environmental Project \\ Technology Programs
}

September 28, 1993

PREPARED FOR THE

$$
\text { BEECN }
$$

FERNALD ENVIRONMENTAL MANAGEMENT PROJECT

FERNALD ENVIRONMENTAL RESTORATION MANAGEMENT CORPORATION

P. O. BOX 398704

CINCINNATI, OHIO 45239-8704 
NOTICE FOR OTHER THAN ENVIRONMENTAL REPORTS (INTERNAL SPECIALS, SPECIALS, SUBCONTRACTOR, TOPICAL REPORTS):

THIS REPORT WAS PREPARED AS AN ACCOUNT OF WORK SPONSORED BY AN AGENCY OF THE UNITED STATES GOVERNMENT. NEITHER THE UNITED STATES GOVERNMENT OR ANY AGENCY THEREOF, NOR ANY OF THEIR EMPLOYEES, NOR ANY OF ITS CONTRACTORS, SUBCONTRACTORS NOR THEIR EMPLOYEES MAKES ANY WARRANTY, EXPRESS OR IMPLIED, OR ASSUMES ANY LEGAL LIABILITY OR RESPONSIBILITY FOR THE ACCURACY, COMPLETENESS, OR USEFULNESS OF ANY INFORMATION, APPARATUS, PRODUCT, OR PROCESS DISCLOSED, OR REPRESENTS THAT ITS USE WOULD NOT INFRINGE PRIVATELY OWNED RIGHTS. REFERENCE HEREIN TO ANY SPECIFIC COMMERC IAL PRODUCT, PROCESS, OR SERVICE BY TRADE NAME, MANUFACTURER OR OTHERWISE, DOES NOT NECESSARILY CONSTITUTE OR IMPLY ITS ENDORSEMENT, RECOMMENDATION, OR FAVORING BY THE UNITED STATES GOVERNMENT OR ANY AGENCY THEREOF. THE VIEWS AND OPINIONS OF AUTHORS EXPRESSED HEREIN DO NOT NECESSARILY STATE OR REFLECT THOSE OF THE UNITED STATES GOVERNMENT OR ANY AGENCY THEREOF, OR FERNALD ENVIRONMENTAL RESTORATION MANAGEMENT CORPORATION, ITS AFFILIATES OR ITS PARENT COMPANIES.

DOE-FERMCO PRIME CONTRACT NO. IS DE-AC05-920R21972.

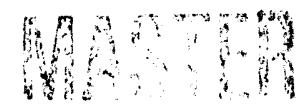




\section{Table of Contents}

0.1 Table of contents

0.2 Table of figures

0.3 Acknowledgements

0.4 Acronyms used in document

i

ii

iii

iv

1.0 Executive summary 1

2.0 Purpose 3

3.0 Introduction 3

3.1 The Fernald Site 4

3.2 Waste storage 5

3.3 Development team 6

4.0 Present waste storage and inspection methodology 8

4.1 Waste storage facilities 8

4.2 Inspection criteria and procedures 16

4.3 Regulatory issues 21

4.3.1 RCRA regulation enforcement 21

4.3.2 DOE and NRC regulations 22

4.3.3 Security regulations 23

5.0 The SWAMI Robot 23

5.1 Goals and benefits 24

5.1 Specifications and technical description 26

$\begin{array}{ll}5.2 \text { Safety systems } & 28\end{array}$

5.3 Operation 29

6.0 Fernald site requirements for SWAMI operation 32

6.1 Functional requirements 33

6.2 Required approvals 34

6.3 Quality assurance and control 36

7.0 Regulatory approval for SWAMI operation 37

8.0 Database integration 39

8.1 Introduction to the SWIFTS database 40

8.2 Proposed SWAMI integration 41

9.0 Conclusions $\quad 43$

10.0 Contacts list $\quad 44$ 


\section{Table of Figures}

Figure 1 Map of the FEMP and demo areas 9

$\begin{array}{lll}\text { Figure } 2 \text { Typical ramp detail } & 10\end{array}$

Figure 3 Drum and box dimensions 10

Figure 4 Hazardous materials segregation 11

Figure 5 Typical labeling of drums 12

Figure 6 RCRA inventory labels 13

$\begin{array}{lll}\text { Figure } 7 & \text { Building } 79 & 14\end{array}$

Figure 8 Tension structure building floor plans 15

Figure 9 Location of hotspots in Building $79 \quad 16$

Figure 10 Typical inspection form 17

Figure 11 Leaker inspection categories 18

Figure 12 Dent/bulge status 19

Figure 13 Corrosion inspection categories 20

Figure 14 Artist's rendering of the SWAMI robot 25

Figure 15 SWAMI path control 31

Figure 16 Proposed SWIFTS Integration 41 


\section{Acknowledgements}

The author would like to thank the many people who have contributed to this document. This includes many 'Unknown Contributors', omitted here in our quest for brevity.

Mike Catalan is an engineering co-operative student who collected much of this information. He also wrote first drafts of several sections.

John Eckstein, manager of low level and RCRA waste storage and disposition, has been an active and enthusiastic participant in this process. Greg Paulson, and Jesse Sosby are RCRA storage facility owners and inspection supervisors and have also been very helpful. Matt Frost supplied much of the information on the Fernald database.

Finally the author wishes to thank clyde ward, robotics technical coordinator for Mixed Waste operations, for his help, encouragement and support, as well as Kurt Peterson, project lead for the SWAMI development effort. 


\section{Acronyms used in document}

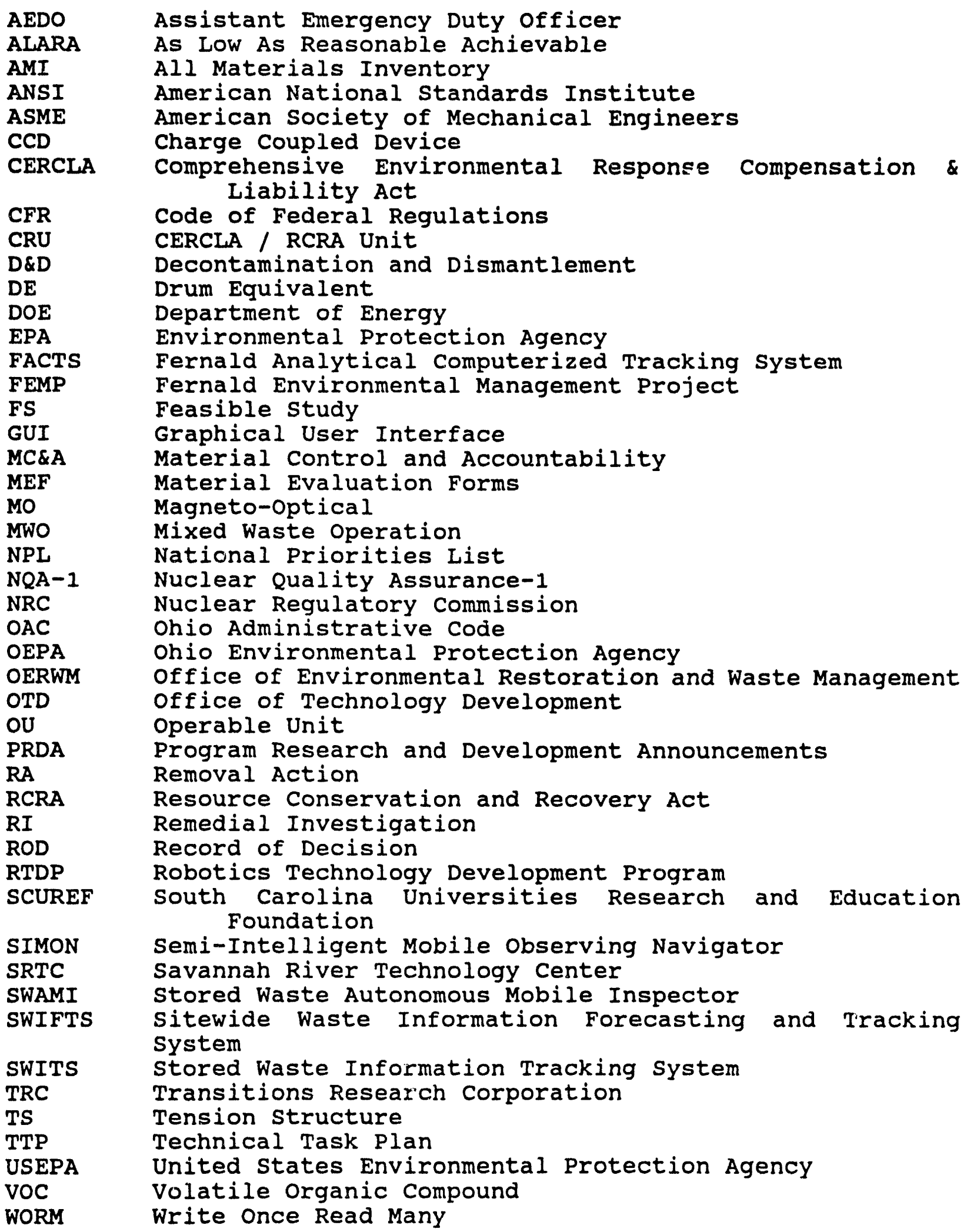




\subsection{Executive summary}

The purpose of this document is to introduce and describe the stored Waste Autonomous Mobile Inspector (SWAMI) robot project and to identify issues that will need to be addressed prior to its field demonstration at Fernald in mid-1995. SWAMI is a mobile robotic vehicle that will perform mandated weekly inspections of waste containers. Fernald has a large inventory of these containers and a need to protect workers from radiation hazards while enhancing the efficiency and effectiveness of the inspections. Intended readers of this document include SWAMI system developers, prospective users, project reviewers, regulators, and any other interested parties.

Weekly inspections of stored waste containers are required by state and Federal regulators under the Resource Conservation and Recovery Act (RCRA). Additionally, the containment area, including the floor and sumps, must be inspected for cracks and the presence of spilled material or water. The main intent of the RCRA mandated waste container inspections is to prevent waste containers from leaking by identifying drums that have started to corrode before they are breached. Storage areas at Fernald have low radiation levels and will permit SWAMI demonstration in an environment similar to waste storage areas with higher radiation, without as much concern for equipment retrieval in the event of a failure. The site, its waste storage facilities and inspection criteria are presented in sections 3 and 4 .

SWAMI is funded by the Department of Energy (DOE). It can identify containers by their bar coded labels and then capture one or more images of the drums, using $C C D$ cameras and strobe lighting, for evaluation by a human in the early stages and by an image processing system later. It will also perform a rad survey of the storage area aisles. A first prototype will be tested before the unit to be field demonstrated is specified and built.

SWAMI will be diligent both in its inspections of the containers and in its rad survey of the aisles. SWAMI never will bore of its job, feel tired, or be distracted. SWAMI will identify drums by their bar coded labels, note their locations, and then collect their images. SWAMI generated reports of container locations will be used to verify the presence and location of the waste inventory. SWAMI will provive timestamped, unalterable documentation of inspection activities and drum condition by archiving images and other findings. The images will subsequently be linked to the specific on-line database record for that container for ease of future retrieval. SWAMI is more fully described in section 5 . 
In the early phases an operator/inspector will be required to view each drum image. Features will be provided to make this as easy as possible. A large color monitor will be used to produce high fidelity images on the screen that an inspector can evaluate at a safe distance from the actual waste. Eventually, a machine vision system will be able to detect rust spots and vertical streaks. A. structured lighting system will be able to detect dents also.

Two buildings have been identified as likely sites for the SWAMI field demonstration. The larger of the two buildings can shelter up to 12,00055 galion drums. Drums stored on pallets in them are usually stacked 3 high though there are some 4 high stacks.

In order to conduct the demonstration at Fernald, several internal organizations will need to assess the safety systems, procedures and equipment quality. The scope and details of their requirements are outlined in section 6 .

In addition, a dialog will be established with regulators to obtain acceptance of SWAMI for its use first as a supplement and eventually to supplant elements of the RCRA inspection. RCRA compliance is monitored by state Environmental Protection Agency (EPA) offices and not by the Federal EPA. Fernald's approach will be to first focus on acceptance of the use of sWAMI in the field demonstration before handling the more general issues of its use in normal daily operations. This is discussed further in section 7 .

The images and other data that SWAMI collects should be entered into Fernald's sitewide waste database so that they can support improved documentation and access. Inventory verification and other SWAMI related applications will require robust communications. SWAMI and this database will have to be integrated in order to yield the maximum benefit from both systems. The database and integration issues are presented in section 8 .

A SWAMI unit that performs at the level presently specified for the second prototype will be welcomed as a vast improvement especially in the area of documentation. Additional features that could be added later to further improve SWAMI have been identified in the course of the site requirements investigation. These include the inspection of fourth level drums, decontaminability, functional self-testing, inspection for proper label placement, and selfreprogrammability based upon real time storage area configuration. 


\subsection{Purpose}

Weekly inspections of stored waste containers are required by state and Federal regulators under the Resource Conservation and kecovery Act (RCRA). The stored Waste Autonomous Mobile Inspector (SWAMI) robot, being developed at the Savannah River Technoloyy Center (SRTC), is intended to supplement manual inspections in the short term. As project specific image understanding algorithms mature, it will become increasingly adept at automatically identifying defective drums.

The purpose of this document is to introduce and describe the SWAMI robot project and to identify issues that will need to be addressed prior to its field demonstration at Fernald in mid-1995. The SWAMI is a mobile robotic vehicle funded by the Department of Energy (DOE) that can identify containers by their bar coded labels and then capture one or more images of the drums for later evaluation by either a human or computer vision system. Intended readers of this document include SWAMI system developers, prospective users, project reviewers, regulators, and any other interested parties.

Fernald's role in this project is to supply the demonstration site and make all necessary preparations. This includes identification of the test areas and plans, and identification and compliance to Federal, state, DOE, and site regulations on system safety and quality. In addition, Fernald will link SWAMI output images to offline mass data storage, and also to an on-line ORACLE database. We shall initiate a dialog with state and Federal regulators towards the near term goal of acceptance of the SWAMI test plan and a longer term goal of acceptance of SWAMI as a supplement and improvement to present mandated RCRA inspections.

\subsection{Introduction}

The SWAMI project represents a complex activity that will involve several groups at different facilities and research centers. Most system design and integration will be performed by engineers at Savannah River Technology Center (SRTC). Navigation enhancements are being developed at Georgia Tech under contract to SRTC. Martin Marietta Astronautics will be developing image analysis software. Field demonstration support activities are being carried out at Fernald.

In this section, background information on the Fernald site is presented and clean-up and waste storage issues are discussed. The point is not only to discuss Fernald, but also to illustrate an example of a DOE remediation site. The SWAMI development team, the preliminary test plan, and related projects are then presented. Present and future waste storage rationale, volumes, and inspection criteria that the SWAMI robot will encounter are discussed in section 4 . 
Section 5 describes the SWAMI robot in detail. Site requirements that have been identified over the past year are laid out in section 6 . The approach for obtaining regulatory approval for SWAMI demonstration and use is described in section 7. A plan to integrate SWAMI data inputs and outputs with a site-wide materials database is found in section 8. This is followed by brief concluding remarks.

\subsection{The Fernald site}

The Fernald Environmental Restoration Project (FEMP) is a government owned, contractor operated facility that refined, smelted, and machined high quality uranium metal for the DOE for over thirty years. The 136 acre production area is situated on 1050 acres of land 18 miles northwest of cincinnati, ohio. In 1989 production ceased and Fernald's mission changed to one of site remediation and waste management. It is presently being managed by FERMCO, a wholly owned subsidiary of Fluor Daniel. A map of the site can be found in Figure 1.

During production operations much of the site became contaminated with uranium and its daughter products. Other hazardous materials such as heavy metals and Volatile organic Compounds (Voc's) were also used. Several football field-sized pits have been filled to depths of up to thirty feet with production wastes.

Due to the fact that the site sits over a large aquifer supplying drinking water to many local communities, it was placed on the National Priorities List. (NPL), along with the other 'superfund' sites, in 1989. Compared to other DOE sites, radiation levels at Fernald are quite low though the total amount of radioactively contaminated material is fairly high. Besides being the first DOE site to undergo complete shutdown and decommissioning, Fernald will be a proving ground for technologies that will subsequently be used to tackle even larger challenges at other DOE sites.

As an NPL site, Fernald must follow the remediation steps laid out in the Comprehensive Environmental Response compensation and Liability Act, as amended (CERCLA) while also adhering to RCRA regulations that cover the generation, transportation, storage and disposal of hazardous wastes. The CERCLA process for site remediation, which is being followed at Fernald and emphasizes thorough investigation and planning prior to the actual clean up. It also suggests subdividing a cleanup site into operable Units (OU's), grouping by commonality of contaminate, location, or physical form. 
The Fernald site has six operable units. OU 1 is responsible for engineering and project management for the cleanup of the large waste pits. OU 2 handles other landfills on site. OU 3 has responsibility for the Decontamination and Dismantlement (D \& D) of all contaminated process buildings and the equipment within them. OU 4 will direct remediation of the three silos. OU 5 is the groundwater and soil remediation. OU 6 , which is the overall site operable unit. Most of the actual design, construction, and remediation activities will be performed by subcontractors.

Under CERCLA, a Remedial Investigation (RI) is first conducted to determine the release or threat of release of contamination. Identified hazards that are threats to health or the environment are slated for Removal Action (RA), in which particularly acute problems can be remedied on an accelerated schedule. Otherwise, a Feasibility study (FS) follows, in which different remediation alternatives are studied in order to identify the quickest, lowest cost and safest strategy. A final plan, prepared by the contractor and the DOE, is then presented to the EPA and, if accepted, becomes a Record of Decision (ROD), defining most details of the remediation plan. The actual cleanup work can then proceed.

The ROD's are not due soon because the CERCLA processes of remedial investigations and feasibility studies are on going at the various operabie units. The years allow enough time to develop alternatives. The long timetable both helps and hinders new technology developments such as the SWAMI robot. Through early demonstrations, new systems like SWAMI can be proven and included in future plans. However, since so much is unknown at present about the eventual course of the clean-up activities, including how clean the site should be rendered, it is difficult to know the exact situations that the systems will be operating under.

\subsection{Waste storage}

Over 100,000 Drum Equivalents (DE's) of process waste are presently stored in individual drums and/or metal boxes on site. Materials in these containers range from contaminated work clothes, tools, and gloves, to magnesium fluoride used in the uranium refining process, to used solvents and rags. In addition to material generated from Fernald processes, additional waste has been received from other DOE sites. The most notable example of this is Thorium that has been accumulating on site since Fernald was designated by DOE as its official DOE repository for thorium. This is the most radioactive material onsite and the only one that requires shielding or clothing for a person to walk nearby.

Waste management requirements and practices were historically less stringent than they are now. Many drums were stored outside for long periods of time. Other waste was stored indoors, although several buildings had leaky roofs. The result was that many drums severely corroded and are now are being 'overpacked' into larger 
containers. Better indoor spaces have been built, though present storage need exceeds capacity and thus old process buildings are being utilized as waste storage areas. New tension structures, semi-permanent buildings built of a light steel frame and thick plastic skin, have been built to accommodate the increased demand. The remaining drums in outside storage are on concrete pads, that lessens the possibility of a release or threat of release into the environment.

Waste constituents must be identified in order to properly store, treat or dispose of the material. Drums of similar materials are stored together while mutually reactive substances must be separated. Waste shipped offsite is directed to one of several different disposal facilities depending on the waste constituents. Facilities generally have very stringent restrictions on what wastes are and are not acceptable. For this reason, drum contents must be sampled and analyzed if there is any question about what was originally deposited into it. In lieu of sampling, a knowledge of process determination can be made, provided that there is knowledge of the hazardous characteristics of the waste or of the processes used, and have sufficient data to do document the knowledge.

While some waste streams, including Thorium, are presently being shipped offsite for disposal, other classes of waste, such as mixed waste (Radioactive and hazardous), cannot yet be disposed since there is no disposal facility available. Additional waste will be accumulating from removal actions in the short term and the major cleanup activities surther down the road.

It is possible that a long-term storage facility will eventually be constructed on site though no decision has yet been made. In any case, storage of waste containers, and their wees.ly RCRA inspection, will be required for the foreseeable future.

\subsection{Development plan and team}

The SWAMI is funded by the Department of Energy (DOE), through the office of Environmental Restoration and Waste Management (ER/WM) . The ER/WM office is responsible for the clean-up and proper disposal of contaminated waste, buildings, process equipment and land at most DOE sites.

The office of Technology Development (OTD) is the ER/WM office responsible for developing technologies that promise to enhance the safety, efficiency, and cost-effectiveness of the remediation activities. The scope of OTD activities is limited to the development and demonstration of systems, and does not include the operational field deployment of proven techniques. 
The Robotics Technology Development Program (RTDP) within OTD focusses on developing robotic systems that address real needs in the ER/WM community. The development work is performed by national laboratories, industry, universities, and/or the DOE sites. The SWAMI robot is being developed and integrated at savannah River Technology Center (SRTC), one of several sites where robotics work is coordinated for the entire RTDP. SRTC coordinates the development of robots to assist in Mixed Waste Operations (MWO).

Savannah River's development plan includes the fabrication and test of a first testbed, SWAMI I, before the second, field demonstrated prototype is built (SWAMI II). Both units will be commercially available mobile robots, outfitted with additional video, rad sensing and bar code scanning equipment. The second robot's specification and design will reflect lessons learned from the first prototype, as well as Fernald requirements. Image understanding software will be later integrated in order to allow the robot to evaluate the container images that it collects. Even without this, SWAMI II will reduce the radiation dose received by inspectors, promote more vigorous and systematic inspection, and provide better documeniation and integration with extant and future waste information resources.

Engineers at Fernald will coordinate with SRTC and focus their efforts on preparing the site and regulatory environment for a successful demonstration in 1995, as well as interfacing with those actually responsible for Waste storage Area inspections. They may also hecome involved in the design and implementation of software for user support and database integration. The Materials Management department of FERMCO will also participate in the planning and evaluation of the first prototype, and in the specification of the SWAMI II. Additional FERMCO support and compliance assessment staff will be utilized to prepare for and accomplish these tasks.

Similar systems are also being developed by two other institutions under Program Research and Development Announcements (PRDA's) issued by the DOE's Morgantown Energy Technology Center. Martin Marietta Astronautics in Denver is developing a container inspection robot using a new mobile base design. It will be demonstrated at Hanford. They have experience in the development of successful vision systems and some of that work will be incorporated into the final SWAMI system. The south Carolina Universities for Research and Education Foundation (SCUREF) is developing arother inspection robot that will be built around a commercial robot, the Cybermotion model K3A robot, over a longer period of time. The following dates indicate latest start times for the proposed timetable:

Demonstrate SWAMI I at SRTC (SRTC)

Send proposed SWAMI inspection criteria to the EPA (FEMP)

Place order for SWAMI II (SRTC, FEMP)

Demonstrate improved SWAMI I (SRTC)

Implement Martin Marietta subsystems on SWAMI I

Install SWAMI II at the FEMP (FEMP, SRTC)

Complete initial field demonstration
$12 / 15 / 93$

$3 / 31 / 94$

$3 / 31 / 94$

$6 / 30 / 94$

$6 / 30 / 94$

$3 / 31 / 95$

$9 / 30 / 95$ 


\subsection{Present waste storage and inspection methodology}

In this section a more detailed background of the present waste storage and inspection methodologies are presented. It is important for developers and users of the new SWAMI robot to understand how inspectors do their job presently, as well as the physical environment in which the inspections are conducted. Additional introductory material on the history, background, and types of our waste and waste storage areas have previously been presented in section 3.2 .

\subsection{Waste storage facilities}

As previously indicated, present waste storage facilities range from outdoor storage on concrete pads, to unused space in former processing buildings, to recently constructed Tension support (TS) buildings. Figure 1 shows Fernald's 136 acre production area and the three buildings slated for the SWAMI demo are crosshatched, with TS-4 and 5 in the upper rear and building 79 in the mid left of the figure.

Some of the stored waste is RCRA hazardous. Other waste is low level radioactive waste that would otherwise be nonregulated waste except for the fact that it is moderately contaminated with radioactive material. Yet other waste is 'nuclear material' because of the potential to remove, recycle and/or re-sell the still valuable fissionable constituents. The remainder, and largest share, of the waste is 'Mixed waste' where it is RCRA waste and radioactively contaminated. The only waste that is sufficiently radioactive to merit personnel protection, the thorium, will be shipped offsite before the SWAMI robot is field demonstrated in 1995.

RCRA waste storage areas must meet a number of criteria relating to the design and construction of the facilities. It should be noted that many present storage locations have been 'grandfathered' from the era where restrictions were less strict and these facilities are being phased out as new ones become available.

Containers with free liquids within them must be stored in diked areas so that in the event of a leak, any material spilling from them is contained. Ramps are built over the dikes so that material handling equipment (and eventually the SWAMI robot) can access the storage areas. Figure 2 shows dimensions of these ramps as they are typically found in the newer RCRA storage facilities. 


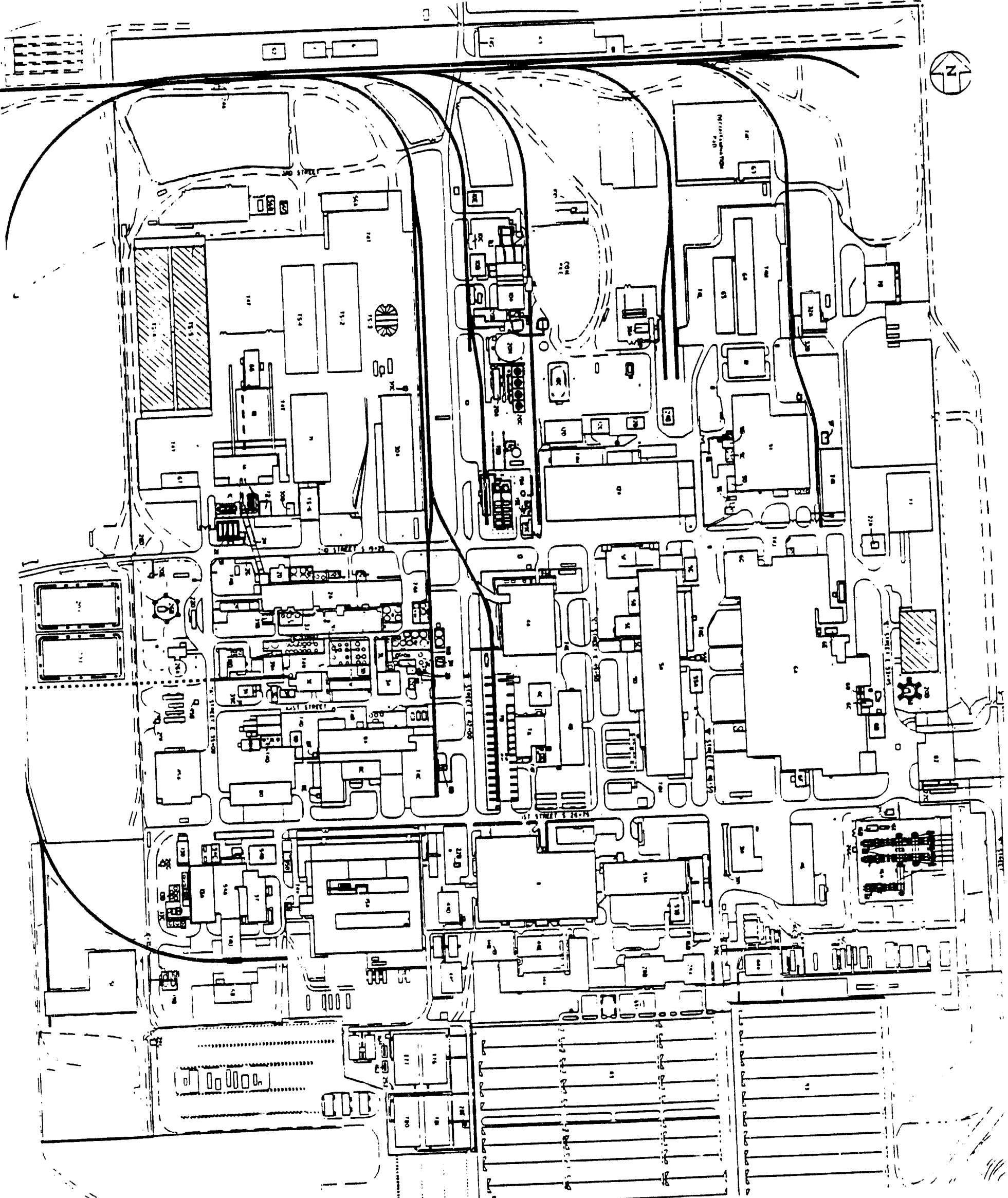

Figure 1- Map of the FEMP. Demo storage areas TS-4,5, Bldg. 79 are crosshatched 


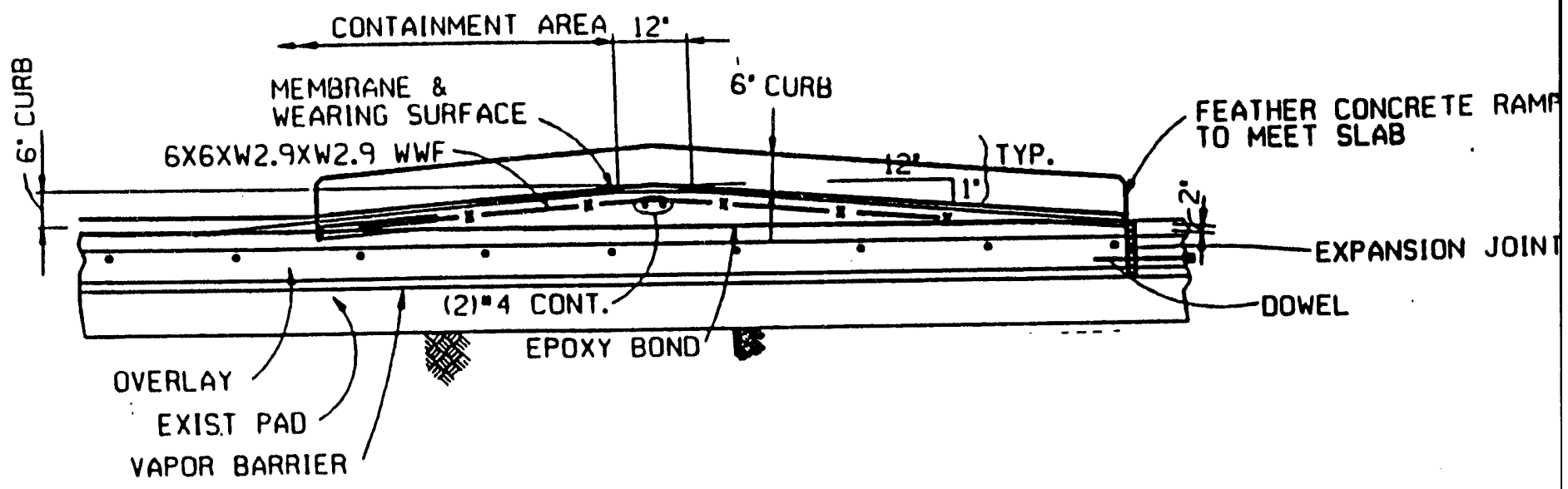

Figure 2- Typical ramp detail- Not to scale

A number of different types of containers are used to store waste. Most is stored in 55 galion drums, though several other sizes are used, especially when decrepit containers are 'overpacked' into larger ones. Generally overpacking involves placing a drum in another of the next largest size, where 55, 85, and 110 gallon drums are available. The five gallon container is mostly used to store samples taken out of other drums. B-25 boxes are now being used more often because their larger size and more regular rectangular shape improves storage efficiency. The B-25's are also called 'six-packs' because they can accommodate six 55 gallon drums. Most RCRA waste is currently in drums, however.

The containers (except B-25's which accept forks of lift trucks) are stored on pallets in the storage facility and there is a weight limitation of 6,000 pounds per pallet. Topmost pallets can hold multiple drum sizes whereas lower level need to have drums of the same size in order to maintain stability of the stack.

\begin{tabular}{|l|ccccc||}
\hline DRUM VOLUME (GAL) & 5 & 55 & 85 & 110 & B-25 \\
\hline \hline Height (In) & 13 & 35 & 40 & 43 & 48 \\
\hline Dia. or (W $\times$ L) & 12 & 24 & 28 & 30 & $45 \times 60$ \\
\hline Number per pallet & 16 & 4 & 3 & 2 & N/A \\
\hline
\end{tabular}

Figure 3- Drum and B-25 box dimensions and pallet loading

Figure 3 shows typical container dimensions and pallet loading. For completeness, note that pallets are typically 4" high, so that a three high stack of 55 galion drums is 9.75 feet tall and a four high stack is 13 feet tall. 


\begin{tabular}{|c|c|c|c|c|c|c|c|c|c|c|c|c|}
\hline $\begin{array}{l}\text { REACTIVITY } \\
\text { GROUP } \\
\text { DESCRIPTION }\end{array}$ & $\begin{array}{l}\text { REACTIYITY } \\
\text { GROUP CODE } \\
\text { (RGC) (1) }\end{array}$ & $A$ & $B$ & C & $D$ & $E$ & $F$ & $\mathbf{G}$ & $H$ & 1 & $\mathrm{~J}$ & $K$ \\
\hline $\begin{array}{l}\text { Nitriles, Halogenated } \\
\text { Organic }\end{array}$ & A & $x$ & $x$ & 0 & 0 & $x$ & $x$ & $x$ & 0 & 0 & $x$ & $x$ \\
\hline $\begin{array}{l}\text { Combust tbles } \\
\text { (hydrocarbons) }\end{array}$ & B & $x$ & $x$ & 0 & $x$ & $x$ & $x$ & $x$ & $x$ & 0 & 0 & $x$ \\
\hline $\begin{array}{l}\text { Mineral acids and } \\
\text { other corrosive } \\
\text { nixtures }\end{array}$ & C & 0 & 0 & $x$ & 0 & 0 & 0 & 0 & 0 & 0 & 0 & 0 \\
\hline Caustics & 0 & 0 & $x$ & 0 & $x$ & 0 & $x$ & $x$ & $x$ & 0 & 0 & $x$ \\
\hline $\begin{array}{l}\text { Toxic Metals and Metal } \\
\text { Compounds }\end{array}$ & E & $x$ & $x$ & 0 & 0 & $x$ & $x$ & $x$ & $x$ & 0 & $x$ & $x$ \\
\hline Fluorides (inorganic) & $F$ & $x$ & $x$ & 0 & $x$ & $x$ & $x$ & $x$ & $x$ & 0 & $x$ & $x$ \\
\hline $\begin{array}{l}\text { Water-containing } \\
\text { Mixtures }\end{array}$ & 6 & $x$ & $x$ & 0 & $x$ & $x$ & $x$ & $x$ & $x$ & 0 & 0 & $x$ \\
\hline $\begin{array}{l}\text { Cyanide Solutions and } \\
\text { Compounds }\end{array}$ & H & 0 & $x$ & 0 & $x$ & $x$ & $x$ & $x$ & $x$ & 0 & 0 & $x$ \\
\hline Strong Oxidizers & I & 0 & 0 & 0 & 0 & 0 & 0 & 0 & 0 & $x$ & 0 & 0 \\
\hline Free Metals & $\mathrm{J}$ & $x$ & 0 & 0 & 0 & $x$ & $x$ & 0 & 0 & 0 & $x$ & 0 \\
\hline $\begin{array}{l}\text { Ignitable (Alcohols, } \\
\text { D001) }\end{array}$ & $k$ & $x$ & $x$ & 0 & $x$ & $x$ & $x$ & $x$ & $x$ & 0 & 0 & $x$ \\
\hline
\end{tabular}

Figure 4- Hazardous materials segregation/separation chart $\mathrm{X}=$ Safe; $0=$ Unsafe

There are additional restrictions on the types of material that may be stored next to each other. These restrictions are summarized in Figure 4 .

The waste containers must be properly marked in order to comply both with RCRA regulations and site requirements. Figure 5 illustrates the types and proper placement of labels required on waste bearing drums. As shown, a drum's labels are distributed around the drum seam. Additional markings are found on drums containing nuclear materials as follows, where band refers to the color of a radial stripe around the drum:

$\begin{array}{ll}\text { Red drum, No band } & \rightarrow \\ \text { Black drum, red band } \rightarrow & \rightarrow\end{array}$ Black drum, yellow band $\rightarrow$ Black drum, green band $\rightarrow$ Blk or White, blue band $\rightarrow$
Enriched reatricted Uranium, $>2.08 U^{235}$ Enriched unrestricted Uranium, $<2.08 U^{25}$ Normal uranium (.718 $\left.\mathrm{U}^{235}\right)$

Depleted uranium $\left(<.718 \mathrm{U}^{235}\right)$ Thorium 


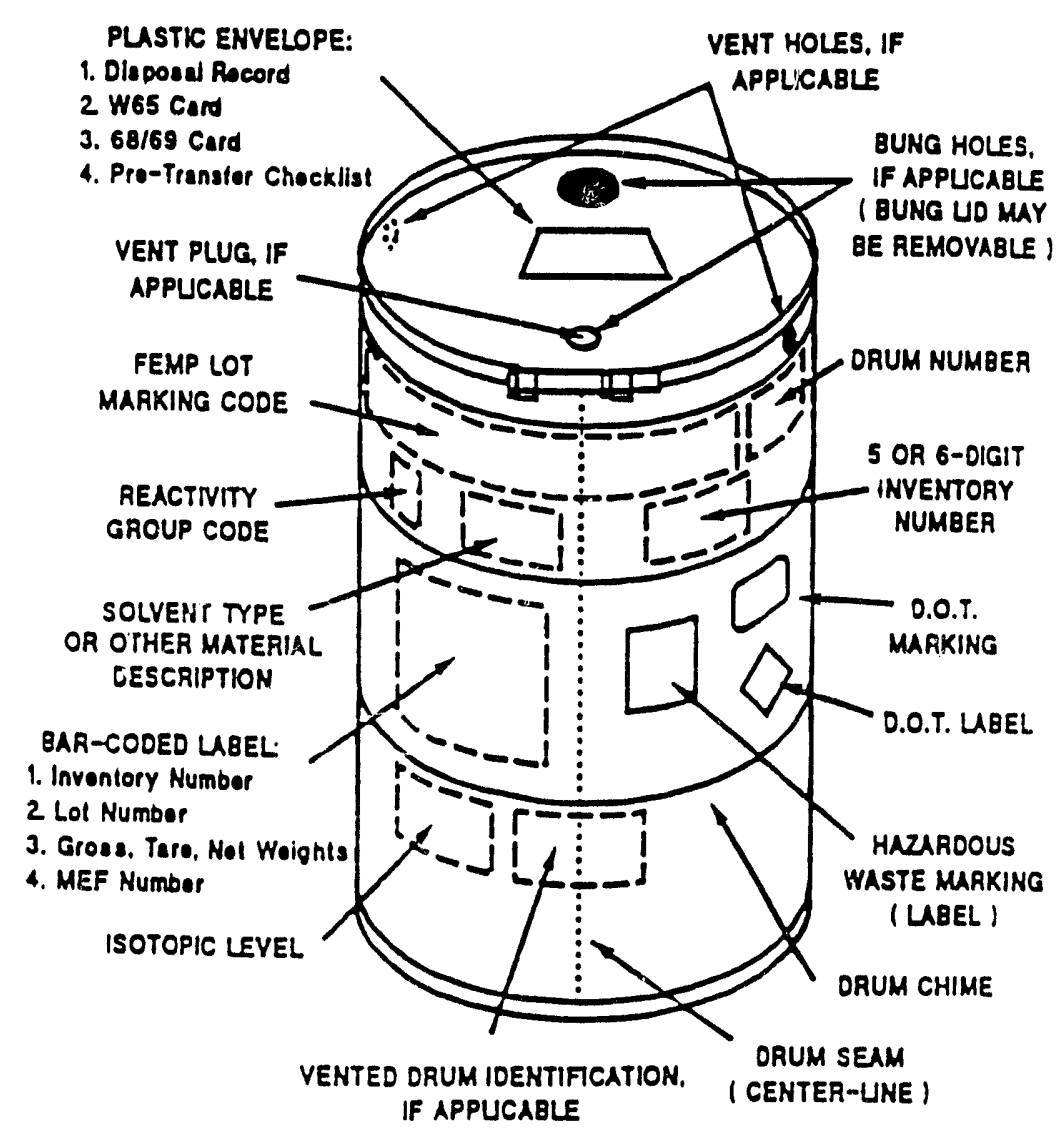

Figure 5- Typical labeling of drums

The bar code labels found on the drums will be of particular concern for SWAMI developers inasmuch as the robot will use the bar coded drum number to determine which one it is inspecting. Presently drums are being labeled with one dimensional bar codes as they are being packed or over packed, this activity is an on going process. An example bar coded label for RCRA waste is illustrated in figure 6. Labels for Low Level Waste and nuclear materials are similar. Two dimensional bar codes implementation is planned for the future.

Drums are stored on pallets in the waste storage areas. They are stacked up to 4 pallets high in the Tension structures and 3 pallets high elsewhere. Pallets are configured to form aisles by starting at the far wall and working towards the center of the building. The result is that only the topmost pallet at the end of the aisle is immediately accessible by forklift, and aisles can be made much more narrow. This enhances packing efficiency though accessibility is more difficult. 


\section{RERA}

\section{INUENTORY NUMBER}
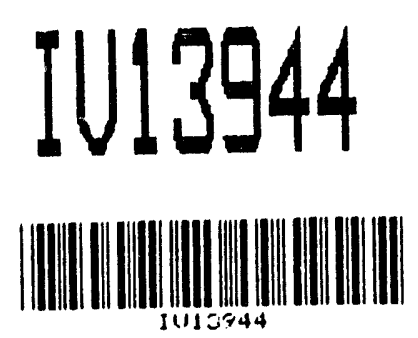

DRUM NUMBER
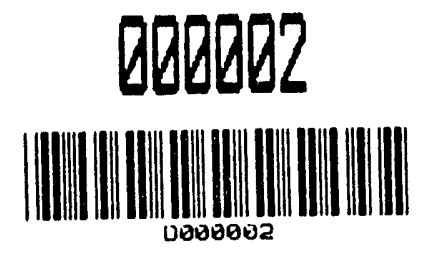

TARE WEIGHT
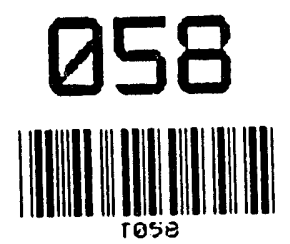

LDT NUMBER
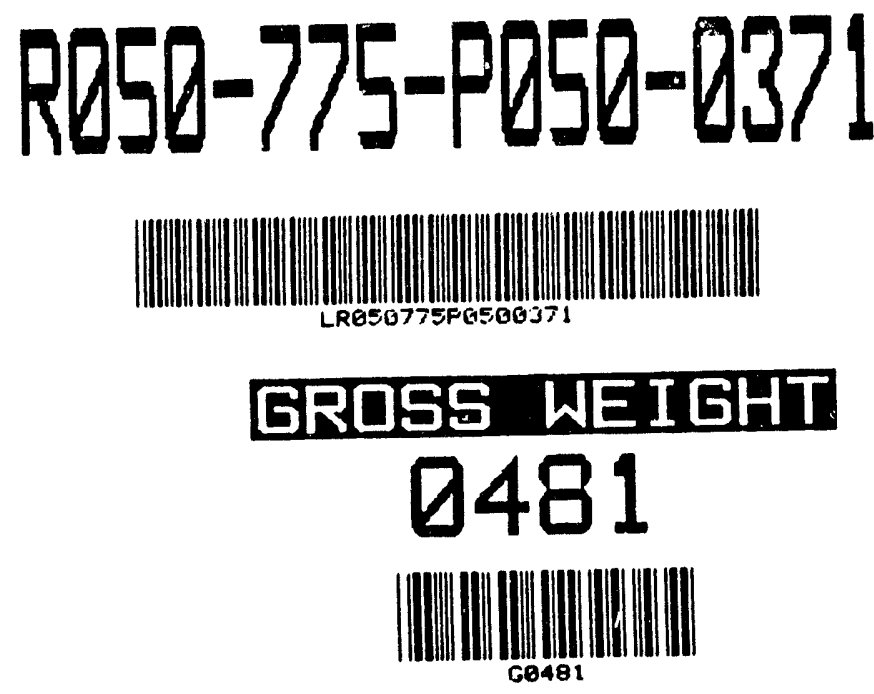

NET WEIGHT
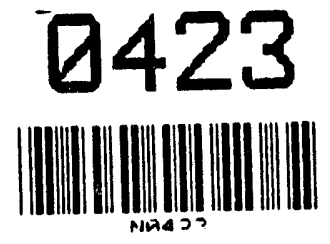

Figure 6- RCRA inventory labels, reduced to $75 \%$ of original size.

RCRA regulations specify that the operator must maintain aisle spacing to allow for the unobstructed movement of personnel, and fire protection, spill control, or decontamination equipment to any area of the facility. This requirement dictates the width of the aisle spacing. The Fernald standard aisle width is 36 " (+2" -0 ") and this is checked by having an inspector walk through the aisles with a 36" long stick to insure safe access for the inspectors.

The interior of the storage buildings are not heated nor cooled, and thus the range of environmental conditions is wide: Typically, humidity can be from 0 to 1008 and temperature from 10 to 90 degrees Fahrenheit. Though it is quite rare for the building temperature to drop below the freezing point, temperature extremes from -10 to 105 degrees Fahrenheit are possible. 
Lighting in the buildings is fairly low and uneven. With the high stacking of the pallets, it is dim in many aisles. The Tension support buildings have natural lighting through the opaque plastic covering, and the diffused light illuminates the space uniformly during daytime hoirs. The floors of the new RCRA storage facilities are all in excellent condition. Building 79 has a smooth concrete floor while that of TS-5 was impregnated with an anti-slip abrasive.

Two buildings have been identified as the likely sites for the SWAMI II field demonstration and are shown in the following figures. They are Building 79 (Figure 7), and TS \#5, located on the concrete pad behind Plant 1. Figure 8 shows the two adjacent TS's \#4 (left) and \#5 (Right). Drum placement is also shown. Recently Bldg. 79 had $220055 \mathrm{Gal}$ drums, $54085 \mathrm{Gal}$, and less than 12110 and 5 Gal drums, as well as overpack and staging areas and an office trailer. 120 Volt AC power at 30 Amps is available in both facilities and 480,3 phase at 60 Amps is also in Building 79. Computer network access is planned though not implemented yet in either building. The longest aisles will be found in TS-5, where they could be as long as 45 feet. The overall dimensions of this building are $90^{\prime} \times 450^{\prime}$, and it can shelter up to 12,00055 gallon drums when pallets are stacked four high. Due to space limitations on site, this high stacking is necessary at the present time.

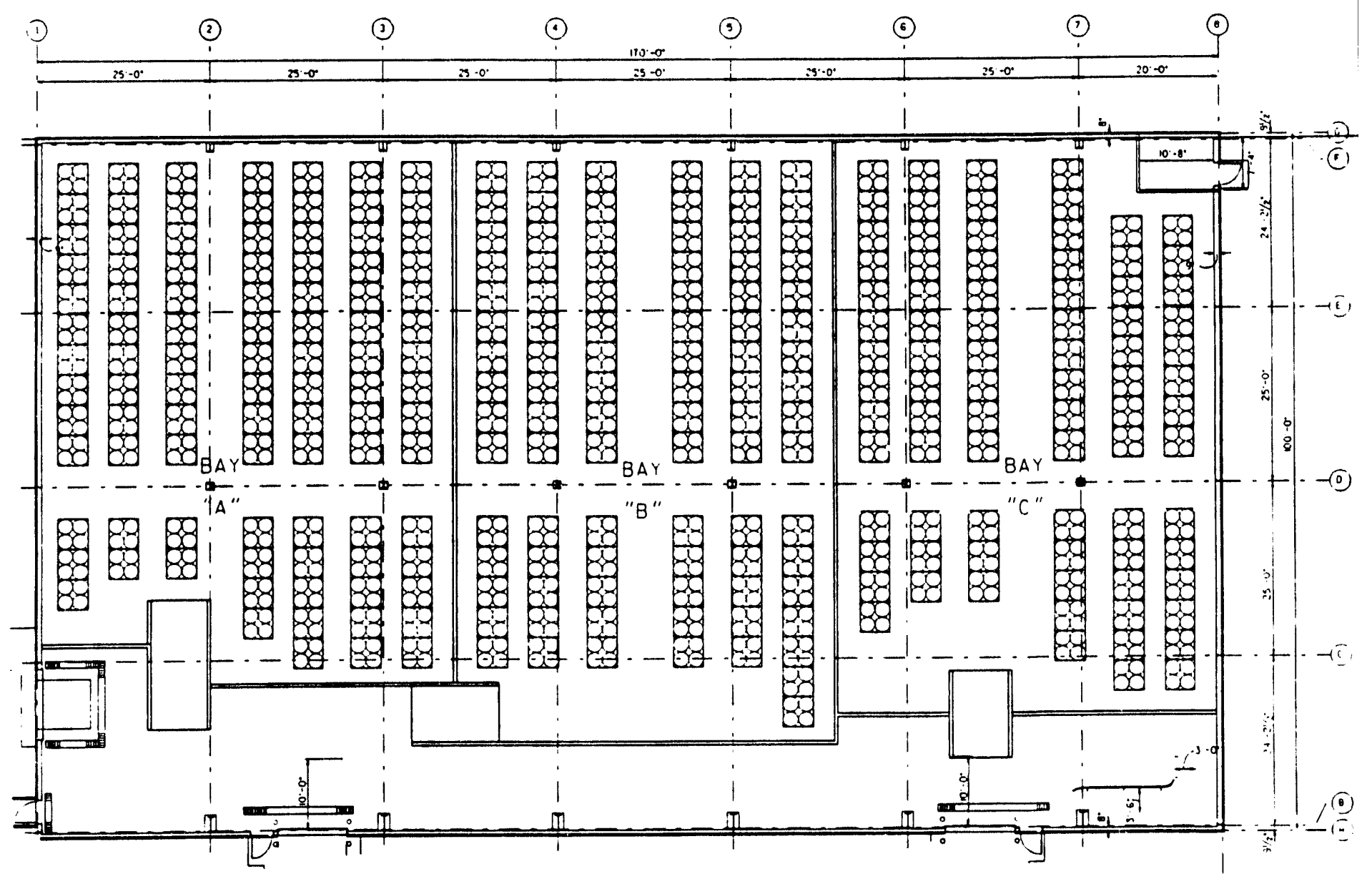

Figure 7- Building 79 (AKA Plant 6 warehouse) 

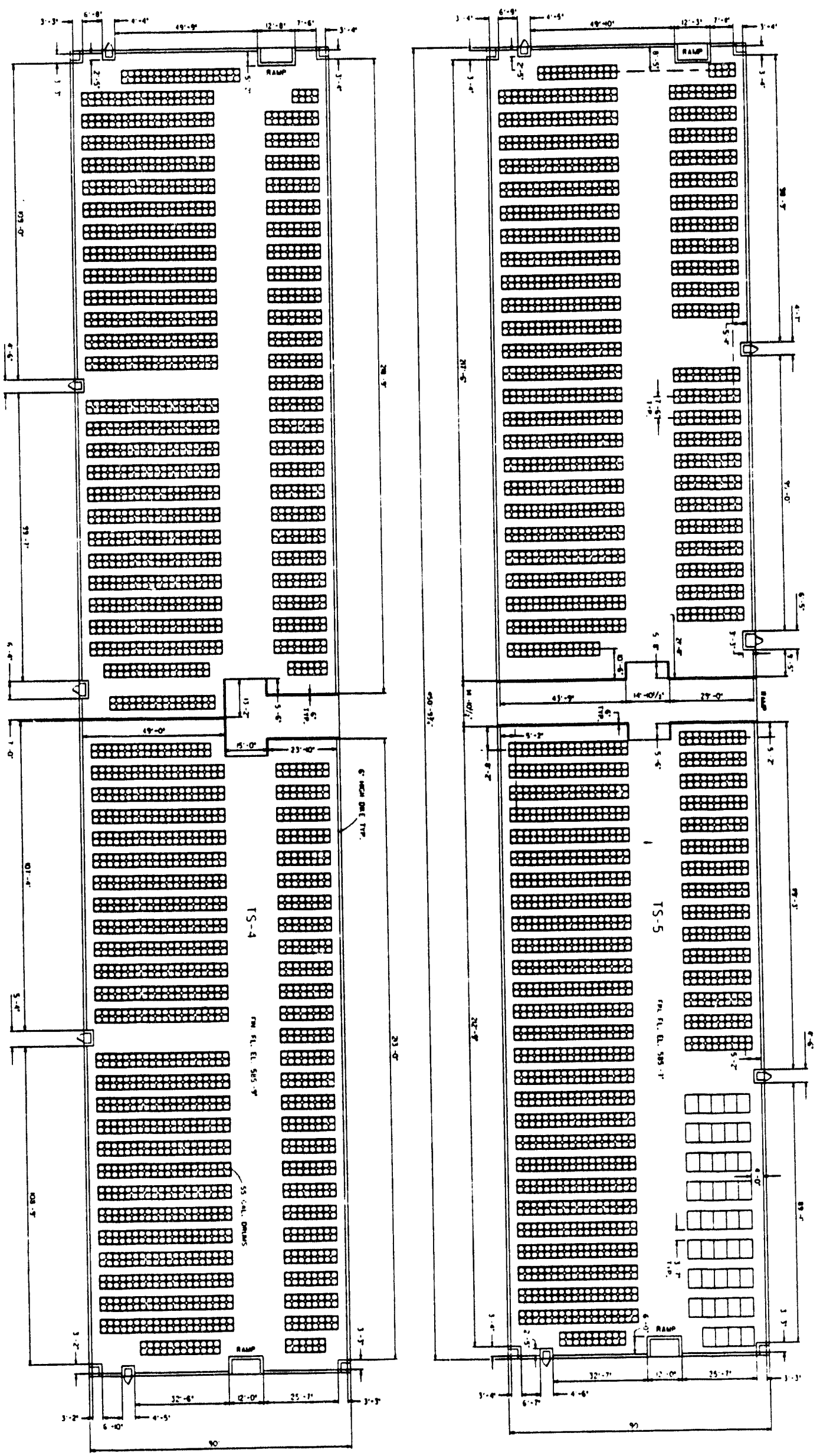

Figure 8-Tension structure building floor plans- TS-4 on left, TS-5 on right 
The centers of TS-4 and TS-5 have two dikes that serve to contain runoff from either half of their length. The TS buildings have the advantage of being regular in their layout and with a wide center aisle. However, it is not possible for a robot to go around the back side of the aisles because of the curvature of the walls and the steel support trusses that jut out from the wall, though the robot can turn around there and backtrack out of the aisle. Building $79^{\prime} \mathrm{s}$ overall size is $170^{\prime} \mathrm{x} 100^{\prime}$. It is more cluttered than the TS's, with diked areas, internal support columns, an office trailer, overpack and staging areas making the space more challenging for a robot to navigate.

Radiation surveys will be conducted in the aisles by the SWAMI robot. A recent rad survey of TS-5 found no areas of elevated radioactivity. In Building 79 , no alpha contamination was found though several minor hotspots of beta/gamma radiation were discovered last winter as marked in Figure 9, at levels between 53 and $77 \mathrm{DPM} / 100 \mathrm{~cm}^{3}$.

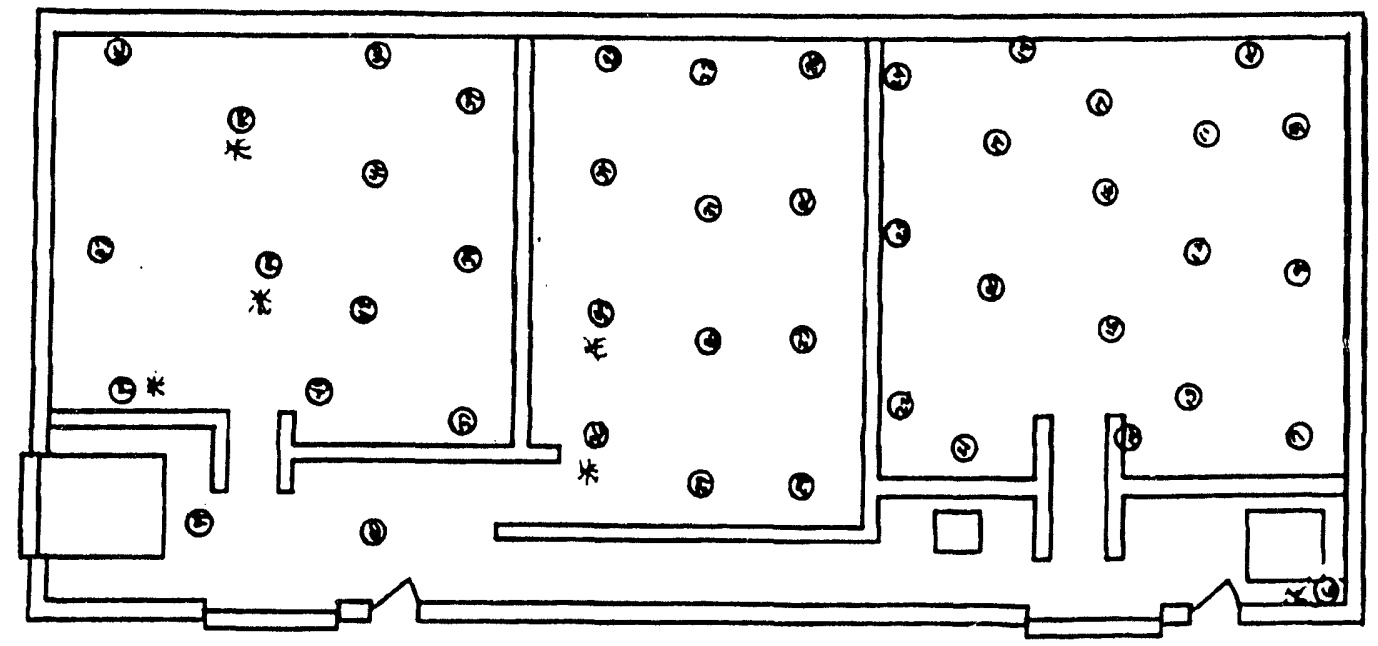

Figure 9- Location of hotspots (asterisks) in Building 79

\subsection{Inspection criteria and procedures}

The main intent of the RCRA mandated waste container inspections is to identify waste containers whose condition may be causing or may lead to a release of hazardous constituents into the environment or a threat to human health. Visual inspections are performed daily and weekly and they are documented on a form similar to that shown in Figure 10. As illustrated, the condition of the containers is only one of a number of items that must be checked weekly. The building, its safety systems, container labeling and waste compatibility are also important features to be checked. The reports become part of a permanent record. If there is a spill or leak the Assistant Emergency Duty officer (AEDO) is notified by the supervisor. 


\begin{tabular}{|c|c|c|c|c|c|c|c|}
\hline & & COUTAIMER & $\begin{array}{r}\text { STORnCE } \\
\text { FOR } \\
\end{array}$ & $\begin{array}{l}\text { AREA } \\
\text { MnND }\end{array}$ & 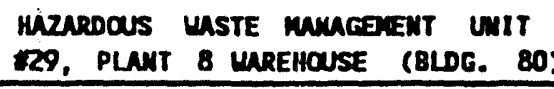 & IMSPECTION FOOEN & \\
\hline & Inepecter's Signature & & & & Date: & Timo: & \\
\hline & Facelitr Omner'o Sigr & & & & Date: & Time: & \\
\hline $\operatorname{man}$ & mEN DEscRuPTION & ACCEPT & REJECT & NA & oeservation & $\begin{array}{c}\text { CORAECTIVE } \\
\text { ACTONS TAKEN }\end{array}$ & $\begin{array}{c}\text { DATE } \\
\text { ACTION } \\
\text { COMPISTE }\end{array}$ \\
\hline 1 & 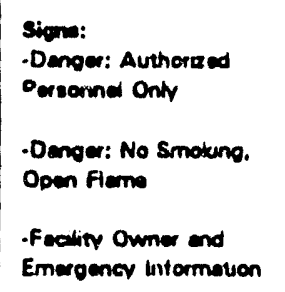 & & & & & & \\
\hline 2 & $\begin{array}{l}\text { Boundery Markere IChen. } \\
\text { stinpl }\end{array}$ & & & & & & \\
\hline 3 & $\begin{array}{l}\text { Condition of was. } \\
\text { buntaing, ped end//or unit }\end{array}$ & & & & & & \\
\hline 4 & 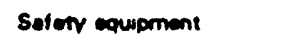 & & & & & & \\
\hline 5 & 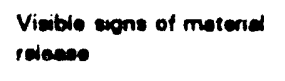 & & & & & & \\
\hline 0 & $\begin{array}{l}\text { Soconderv contenment } \\
\text { condition }\end{array}$ & & & & & & \\
\hline 7 & 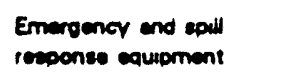 & & & & & & \\
\hline 8 & Contemerer menesorment & & & & & & \\
\hline 9 & Compatibitity codes & & & & & & \\
\hline 10 & Condrtion of contemener & & & & & & \\
\hline
\end{tabular}

Figure 10- Typical inspection form 


\begin{tabular}{|c|c|c|}
\hline TYPE & CHARACTERISTIC & CORRECTIVE ACTION \\
\hline I & $\begin{array}{l}\text { Material flowing from } \\
\text { container and accumulation on } \\
\text { pallet or pad. }\end{array}$ & $\begin{array}{l}\text { 1. Notify supervisor. } \\
\text { NoTE: Supervisor notifies AEDo. } \\
\text { 2. Imuediately stop or contain leak. } \\
\text { 3. Record on inspection form the } \\
\text { container requires mitigation within } \\
24 \text { hours. } \\
\text { 4. Complete additional cleanup as } \\
\text { necessary. } \\
\text { Note: Supervisor shall initiate an } \\
\text { Occurrence Report. }\end{array}$ \\
\hline II & $\begin{array}{l}\text { Material on drum exterior } \\
\text { oniy; no material on pallet or } \\
\text { pad. }\end{array}$ & $\begin{array}{l}\text { 1. Record leak on inspection form. } \\
\text { 2. Notify supervisor. } \\
\text { NOTE: Supervisor shall initiate an } \\
\text { Occurrence Report. } \\
\text { NOTE: Supervisor shall review the } \\
\text { Completef inspection forms to } \\
\text { prioritize containers for } \\
\text { transfer to overpack staging } \\
\text { area and subsequent mitigation. }\end{array}$ \\
\hline III & $\begin{array}{l}\text { Container exterior discolored/ } \\
\text { visible contamination; no } \\
\text { material release. }\end{array}$ & $\begin{array}{l}\text { 1. Record condition on inspection form. } \\
\text { NOTE: Supervisor shall schedule } \\
\text { container for overpacking. } \\
\text { NOTE: Supervisor shall initiate an } \\
\text { Occurrence Report. }\end{array}$ \\
\hline
\end{tabular}

\section{Figure 11- Leaker inspection categories}

During a typical week, three to five suspect containers will be found that require immediate attention out of the 100,000 drum inventory. Suspect containers are ones that are either leaking already or pose an imminent danger of doing so. These drums are overpacked or repackaged in another container. Defined 'leaker' types and response actions are shown in figure 11. 
Presently container inspection is performed visually, with the inspector occasionally scratching a suspicious area with a pocket knife to identify the depth or extent of rust spots. No thickness gages, eddy current, or ultrasound devices are used to check drum integrity and no future need for such sensors has been identified.

Drums are always stored so that the side seam and locking screw for the ring that holds the top down are visible. It has been found that corrosion usually starts along the side or bottom seams of the drum.

The most likely cause of container degradation is corrosion in the form of rust. Dents in the containers can also potentially breach the container or, more likely, act to raise the internal stress of the container in the dented area, thereby making stress corrosion more likely. Certain drums are much more likely to leak because of corrosive material within them, and these are checked more diligently. Also, certain locations in a storage building may promote container decay due to localized leaking of the roof or proximity to outside doors.

Dents in the drum are not considered a problem unless severe. Severity criteria are that the dent has 1 inch or greater depth and width of greater than 6 inches in any other dimension. The exception to this is on the drum rims, where a 0.25 inch depth will cause the drum to be unacceptable. A bulge of greater than 1 inch is also considered unacceptable. The exception to these criteria is for waste containing uranium metal. In this case, a non-leaking holes just below the lid are acceptable for venting. Figure 12 outlines action levels for dented containers.

\begin{tabular}{|c|l|l|}
\hline Type & Characteristic & Corrective Action \\
\hline 1 & $\begin{array}{l}\text { Dents and/or Bulges affect } \\
\text { container to degree or } \\
\text { potential or actual release }\end{array}$ & $\begin{array}{l}\text { Over-pack or transfer } \\
\text { to new container }\end{array}$ \\
\hline 2 & $\begin{array}{l}\text { Dents and/or Bulges not } \\
\text { affecting container } \\
\text { integrity }\end{array}$ & Continue to monitor \\
\hline 3 & $\begin{array}{l}\text { No visible dents and/or } \\
\text { bulges on the container }\end{array}$ & No action necessary \\
\hline
\end{tabular}

Figure 12- Dent/bulge status 
Action and response levels for different corrosion categories are presented in Figure 13. As a rule, containment ability is not affected by general external corrosion if only paint and/or minor metal flaking is occurring. Blisters on drums should be examined to determine whether it is due to a lack of paint adhesion or corrosion of the metal underneath. A more specular, or shiny, surface indicates that only the paint is blistering and thus the corrosion is less severe.

\begin{tabular}{|c|c|c|c|c|}
\hline \multirow[t]{2}{*}{ CATEGORY } & \multirow[t]{2}{*}{ CHARACTERISTIC } & \multicolumn{2}{|c|}{$\begin{array}{l}\text { COULD CAUSE LOSS } \\
\text { OF DRUM INTEGRITY } \\
\end{array}$} & \multirow[t]{2}{*}{ CORRECTIVE ACTION } \\
\hline & & YES & No & \\
\hline A & $\begin{array}{l}\text { Severe corrosion } \\
\text { with deep pitting } \\
\text { and/or metal fiaking }\end{array}$ & $x$ & & $\begin{array}{l}\text { As directed by supervision } \\
\text { MOTE: Disposition shall be } \\
\text { within } 24 \text { hours. }\end{array}$ \\
\hline B & $\begin{array}{l}\text { Corrosion with } \\
\text { shallow pitting } \\
\text { and/or mild metal } \\
\text { flaking }\end{array}$ & & $x$ & As directed by supervision \\
\hline C & $\begin{array}{l}\text { Surface rust with no } \\
\text { pitting and mild } \\
\text { paint flaking which } \\
\text { exposes bare metal }\end{array}$ & & $x$ & $\begin{array}{l}\text { Remove rust and flake paint } \\
\text { and paint as scheduled by } \\
\text { supervisor }\end{array}$ \\
\hline
\end{tabular}

Figure 13- Corrosion inspection categories

Drum lids can develop large areas of corrosion due to moisture collecting on their surface. The situation is magnified since paint, moisture, and/or corrosion products cannot fall away but remain on the surface. This type of corrosion does not have as dramatic an effect on drum integrity as side or bottom corrosion and thus it is more acceptable here than in those other places.

Deeper flaking or the formation of corrosion products into dark nodules indicates a more severe localized attack. These nodules can also be identified by relief and other textural cues. Deep pitting is also a sign of imminent container collapse, and even a small number of small diameter pits should be taken seriously. 


\title{
4.3 Regulatory issues
}

In this section the key regulations which dictate the need for inspections and outline the way they are carried out are described. The RCRA regulations are promulgated by both Federal and state agencies and are discussed first. Requirements dictated by the DOE and/or NRC (Nuclear Regulatory Commission) are then presented. Security issues may come up at some sites and are also introduced.

New regulatory guidance and agreements may need to be developed in order for SWAMI to be accepted first as a supplement to human inspections and eventually to supplant some aspects of the RCRA mandated inspections. These issues will be explored further during the coming fiscal year and the general approach that will be taken is presented in section 7.0 .

\subsubsection{RCRA regulation enforcement}

The U.S. Environmental Protection Agency (U.S. EPA) is responsible for the enforcement of hazardous waste regulations such as RCRA and CERCLA. The EPA presents the regulations for which it is responsible in Title 40 of the code of Federal Regulations (CFR).

Applicable regulations for waste storage at interm status facilities at 40 CFR are found in Part 265, "Interim status standards for owners and operators of hazardous waste treatment, storage, and disposal facilities". The SWAMI system will function under 265.15 General Inspection Requirements. The basic intent of the regulation is outlined in the first paragraph:

\begin{abstract}
"The owner or operator must inspect his facility for malfunctions and deterioration, operator errors, and discharges which may be causing- or may lead to: (1) Release of hazardous waste constituents to the environment or (2) a threat to human health. The owner or operator must conduct these inspections often enough to identify problems in time to correct them before they harm human health or the environment"
\end{abstract}

The U.S. EPA authorizes states to implement and enforce their respective hazardous waste programs in lieu of the federal program (RCRA) when a state program is at least as stringent as the federal program. The state of ohio has an authorized program, which is implemented and enforced by the OEPA. For purposes of this paper, references to the federal regulations will also mean the authorized program of Ohio. The Ohio Administrative Code (OAC) that apply to container inspection, $\$ 3745-55-70$ to $\$ 3745-55-78$, are identical to their federal counterparts. 
The facility that stores the waste must be inspected to insure its integrity. The inspections required include the equipment in the facility. The SWAMI system will be part of the equipment in the storage facility and may therefore fall under these guidelines. The SWAMI system must have a written schedule for preventative maintenance and testing.

The results of the inspections of the SWAMI system must be stored in written form for a minimum of three years. These records must include the date, time, name of inspector, and observations from each inspection. If repairs are necessary, records of the repair activity must be included.

According to in part 40 CFR 265.73 operating Record certain information must be maintained for the duration of the operation of the storage facility. This information includes a description and quantity of the waste, the date received, location and quantity of the waste within the storage facility, and cross-references to the manifest document numbers.

The waste that the SWAMI system will inspect is stored in containers. 40 CFR 265.170 (OAC 3745-55-73), Use and Management of containers applies to this stored waste. The waste containers must be inspected to insure that they are in good condition. The inspections should focus on leaks and deterioration caused by corrosion or other factors. These inspections are to take place at least once a week. The container holding the waste must not be handled or stored in a manner which may cause a loss of container integrity.

\subsubsection{DOE regulations}

DOE order $5820.2 \mathrm{~A}$ addresses the handling of radioactive waste and is organized along the various classifications of waste. Chapter III, Management of Low Level Waste, applies to the Fernald site. S $3 \mathrm{~b}$ states that where practical, the performance of the disposal site is to be monitored inside and outside of the facility. \$ $3 \mathrm{~h}$ requires, among other things, that records be maintained concerning all waste that enters and leaves the facility. In addition, the operations and processes must conform to the Nuclear Quality Assurance-1 (NOA-1) guidelines collaboratively developed by American National Standards Institute (ANSI) and the American Society of Mechanical Engineers (ASME).

In addition to the DOE requirements, the operations and processes must conform to National Environmental Policy Act. Chapter IV, \$3a states in part that all DOE waste "naturally occurring ... radioactive material mixed with $R C R A$ hazardous chemicals shall be managed as hazardous waste under RCRA." 


\subsection{3 security Regulations}

The SWAMI robot could also perform requirement of 40 CFR $\$ 265.14$ security. The facility must have 24 hour surveillance. At some sites, the robot could be modified fairly easily to support sensors to detect intruders and abnormal conditions.

At other DOE sites, SWAMI could perform storage area inspections of specially controlled Special Nuclear Materials or strategic special Nuclear Material. Information concerning this material is considered to be classified under 10 CFR 95. The data collected from the inspection of this material is also classified. 10 CFR 1016 outlines the safeguards that would be required to handle this restricted data The SWAMI system could lower the costs of inspection for classified drums.

\subsection{The SWAMI Robot}

As previously discussed, the stored Waste Autonomous Inspector is a mobile robot that will be able to identify waste containers by their bar-coded labels, capture their images, evaluate those images (in the long term) and perform a radiation survey of the storage area aisles. It is being developed at Savannah River Technology Center in partnership with several other organizations. A first prototype will be laboratory demonstrated by the end of 1993 and a second prototype will be field tested at Fernald in 1995. An artist's rendering of SWAMI is found in Figure 14.

Savannah River Technology Center's robotics program has a long history of supplying remote and robotic systems to support operations at Savannah River in addition to the development work that is performed under the aegis of the RTDP.

The SWAMI robot will benefit from SRTC's experience with the SIMON (Semi-Intelligent Mobile observing Navigator) robot which daily scans corridors for radiation using gas proportional ionization detectors. Built on a Cybermotion robot base unit, SIMON can locate alpha and beta/gamma contamination better than human inspectors, as evidenced by the more than 20 hotspots that SIMON found in areas previously declared to be clean by rad technicians. Experience has found the robot to be both effective and safe in its operations.

As with SIMON, the development strategy for SWAMI will be to use commercially available equipment as much as possible. This includes the base robot itself. The first prototype is built around the HelpMate robot, a product of Transitions Research corporation (TRC). The HelpMate was originally designed to deliver supplies to different locations in hospitals, passing in areas cluttered with people and obstacles. It has operated safely and effectively in hospitals in the several years it has been on the market. 
In this section, SWAMI goals and benefits, specifications, design details, operation and desired features of the user interface will be presented. Safety features are highlighted separately because of their special interest to operations, safety, and risk assessment personnel at Fernald. The SWAMI system will be integrated with a sitewide database to demonstrate the data management, logging, and documentation benefits of SWAMI and these are presented in section 8.0. Some additional operational features of SWAMI that might further enhance SWAMI down the road are presented in section 5.3 .

\subsection{Goals and benefits}

The ultimate goal of the SWAMI system is to supplant human inspector's daily and weekly inspection of waste containers. As previously mentioned, this is one of several inspections of the waste storage areas that must be performed to comply with RCRA regulations. For numerous technical and practical reasons, SWAMI will never be able to monitor all of the items on the inspection checklist. However, the inspection of the waste containers is the longest and potentially most dangerous of those tasks, as it brings the inspectors physically closest to the containers.

Storage areas at Fernald are much less hazardous than most and this will permit SWAMI to be demonstrated in an environment similar to more dangerous waste storage areas without as much concern for decontaminating the prototype or retrieving it in the event of a failure. In many other DOE facilities, alpha, beta and gamma radiation hazards are much higher. Driven by the mandated goal to keep worker exposure As Low As Reasonable Achievable (ALARA), these hazards limit the time inspectors have to do their job. They also result in the need for cumbersome and uncomfortable personal protetection clothing, all of which becomes contaminated trash after a single use.

SWAMI will be thorough both in its inspections of the containers and in its rad survey of the aisles. SWAMI will identify drums by their bar coded labels, note their locations, and then collect their images using Charge Coupled Device (CCD) cameras and strobe lighting. The use of strobes is intended to save power, by only energizing the lights intermittently. SWAMI-generated reports of container locations will be used to verify the presence and location of the waste inventory. It will also have sensors on board that allow it to identify dents in the drums. 


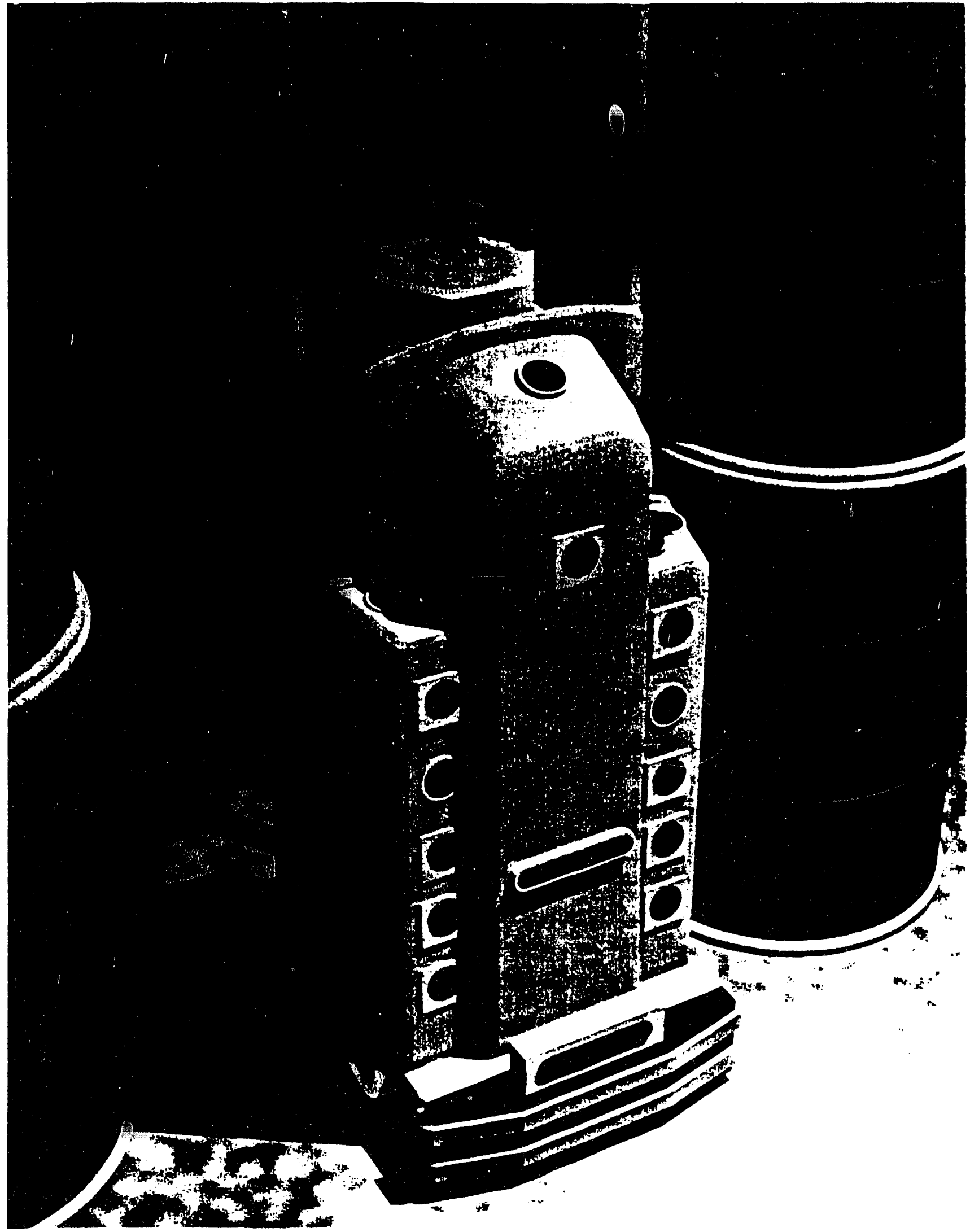

Figure 14-Artist's rendering of the SWAMI robot 
SWAMI will provide timestamped, unalterable documentation of inspection activities and drum condition by archiving images and other findings. The images will subsequently be linked to the specific on-line record for that container for ease of future retrieval. It will be possible to identify containers that tend to deteriorate more quickly (perhaps due to particularly corrosive contents). By merging previously captured images to form a history of one container's degradation, trends will be established that can help predict the likelihood of future deterioration, leading to the overpacking of drums prior to leaking.

In the short term, SWAMI II will present the images it has captured to an inspector who will then review them to identify potentially damaged drums. This will provide the advantage of lower radiation exposure to the inspector and encourage a more thorough inspection of each drum.

Eventually it will be endowed with image processing software that will allow it to identify suspect drums automatically. This will reduce the number of containers that a human must inspect by orders of magnitude. After a full 8 hour mission, the SWAMI unit will generate a report of the suspect drums to an inspector who will be able to access those drum's images. Some fraction of those images would then require a closer inspection to confirm their condition. The goal of the image processing software will be to insure that decrepit drums are never missed even if that means that acceptable drums are erroneously placed on the suspect list.

An additional application of the vision system has been identified and could be included at a later date. As evidenced by figure 5, many labels are required to be affixed to the waste containers. The vision system may be able to identify specific labels through color, size, and location cues. It is unlikely, however, that it could recognize characters and hence 'read' the labels. This could be used to identify mislabelled containers, incompatible containers erroneously stored in close proximity, and missing or damaged labels. This would address a separate task required during the RCRA inspections, and could do it more accurately inasmuch as all of the records that indicate which labels are required could be accessed on-line during the inspection.

\section{2 specifications and technical description}

SWAMI is a modified HelpMate robot and has a maximum forward speed of approximately $3 \mathrm{MPH}$. It can maneuver in a 36 inch aisle. It will be able to operate for 8 hours without recharge; requiring 120 Volts AC at standard current ratings. Wireless transmission between SWAMI and base computer will be broadcast on a spread spectrum of $26 \mathrm{MHz}$ at a frequency of $915 \mathrm{MHz}$ and a power output of 1 watt. It is nominally capable of indoor operation only and thus may need to be slightly modified to withstand temperature and humidity extremes that are anticipated in the unheated waste storage areas. 
Major additions to the robot include bar code scanners, cameras, and strobe lighting; $A$ passive reflector beacon system to confirm and update the robot's position for navigation; A radiation survey system; A structured lighting system to identify dented drums; An on-board VME based computer to supervise and control all of the onboard subsystems, including the HelpMate; Boards for image capture and processing; And a wireless Ethernet transceiver to communicate with the base station computer.

In addition, the HelpMate was factory modified with two sensor packages that are positioned close to the floor on the left and right edges. Each package has four ultrasound detectors that sweep from straight ahead to straight to the side. These are used to center the HelpMate in the aisle by measuring the position of the top board of pallets on both sides of the aisle. Each package also includes photodetectors that return a signal upon finding a strip of reflective tape. This is intended to be used to update SWAMI's internal position estimate. Its use is further discussed in section 5.4 .

The base station will consist of a charging area, operator console for controlling SWAMI and evaluation of SWAMI output, and a computer. The computer will be able to interface with both the SWAMI and the sitewide materials database.

SWAMI will provide an alpha and beta/gamma radiation survey system that can identify contamination within its path of greater that 500 counts per minute. The vehicle must travel 1 inch per second or less (.06 MPH) for this survey, so in an 8 hour long survey, close to $2500 \mathrm{ft}$. of aisle can be surveyed. SWAMI will read machinereadable bar coded labels affixed anywhere on the middle third of drums. The label must be within 40 degrees of the facing aisle.

The on-board video systems will capture $512 \times 486$ pixel full color images from video taken by six cameras with NTSC output. Camera optics include a very wide angle lens $(3.5 \mathrm{~mm}$ focal length) so that the full image of the drum can be captured from the center of fairly narrow aisles. The images will be stored in a JPEG image file (a popular standard) where they can be compressed to 30-60 kbytes per image with no perceptible loss of quality.

The vision system will be able to detect rust spots of a diameter of $1 / 4$ inch or larger. It will also detect vertical streaks larger than $1 / 4$ inch wide and 6 inches long. The structured lighting system will be able to detect dents equal or larger than 1 inch depth, 1.5 inches wide and 2 inches long on the side of the drum and not in the rib area. 
Most sensors will be mounted on vertical masts in order to position them at the correct height for data capture. The masts may need to be motorized in order to adjust for different stacking heights resulting from the various container sizes in use. To limit the variability of boom positions, not all container sizes will be inspectable with SWAMI II, but the vast majority, including 55 and 85 gallon drums, will be covered. SWAMI will be able to inspect three high stacks of pallets and may be modified to suit the fourhigh stacking of the TS-5 storage area.

\section{3 safety systems}

The principal safety concern of the SWAMI is its ability to avoid collisions with people, containers, and other objects. Experience with both the HelpMate and SIMON robot indicate that this should not be a significant problem. Indeed, SIMON's obstacle avoidance has been thoroughly and successfully tested by many of its human co-workers. The HelpMate has successfully demonstrated its obstacle avoidance in the cluttered environment of hospital corridors.

SWAMI has several redundant safety systems to detect obstacles, and robust navigation software that allows the robot to modify its path to avoid the obstacle and then return to its original mission. The maximum deviation from its original path can be specified as will be described in the next section.

Four separate sensor systems are responsible for detection of impending collisions: Ultrasonic range finders, laser scanners, tactile sensors, and a front bumper. Two large emergency 'mushroom' switches are located on the top of the unit in the very unlikely case of failure of the sensors. Generally these sensors have been deployed only on the front and sides of the robot since the standard HelpMate is not designed for significant reverse motion. However, it does have rear collision detection bumpers to protect objects and people behind it during the rare instances in which it backs up. The new HelpMate purchased for the SWAMI II robot will probably have a more complete sensor package on the rear side of the robot so that it can safely back up out of dead-ending aisles.

Multiple ultrasound sensors have been placed on the robot to detect and range obstacles in its path or beside it. These sensors operate by 'chirping' at several frequencies and then waiting for a return echo bouncing off the nearest object in the sound wave's path. Range is determined by measurement of the time of flight between the chirp and the returned echo (the heading angle remains undetermined). These sensors have a fairly narrow beam angle (30 degrees) which is why so many are installed on the robot. Multiple tones are broadcast because some soft materials may absorb sound at some or all of the emitted frequencies. Thin objects are also often missed by ultrasound due to their small cross section. The sensors have a range of 17 inches to 30 feet. 
The laser scanner is intended to be the second line of defense to identify those objects that ultrasound may miss. Deployed on the front of the robot, the system consists of a low power infrared laser and a camera system. The system uses an elegantly simple method whereby planes of light are projected horizontally ahead of the robot. The camera is mounted downward. In the event that an obstacle appears, laser light will reflect back to the camera and will appear on the image. Thus, any light on the image plane is interpreted as an obstacle and closer obstacles will appear at a lower position on the image.

Tactile sensors are copiously mounted on the robot so overhangs, as well as objects missed by the other sensors, can be detected. These sensors are individually wired strips of tapeswitch, enabled upon contact. Once tripped, the robot stops motion immediately, backs up, and goes into its obstacle avoidance routine. By dint of the separate switch segments, the robot can intelligently determine which direction to travel in order to avoid the obstacle.

In the event of failure of the other systems, the robot has a spring mounted front bumper to which a photoelectric pair are mounted. Upon collision, the bumper will compress and break the light beam between emitter and detector, thereby notifying the unit of the event. It will then back up and try to find a better path.

An additional safety concern is SWAMI's behavior in the event of subsystem failure. As envisioned, SWAMI will cease operations and shut down in the event that the HelpMate CPU or locomotion systems break down. In the event of sensor or other subsystem failure, it will return to its base station. The HelpMate unit has built-in failsafe features that ensure that locomotion control is not completely lost in the event of motor drive failures. At any rate, the low maximum speed of SWAMI and the fact that drums are placed on pallets make it improbable for the robot to damage waste containers or people in the event of drive failure. In case of communications failure, a remote control tether can be attached and used to lead the robot back to its base station manually.

SWAMI will perform a complete diagnostic check before it begins its daily operations. This may include interactions with test fixtures at the base station that allow for a thorough, active check of all its sensors and systems.

\subsection{Operation}

SWAMI prefers the night shift so that it can operate without being disturbed by people and equipment in the environment. Conversely this also keeps the robot from disturbing normal daily operations in the waste storage facilities. 
Most of the details of operating procedures and controls interface have not yet been determined. Also, there will be several different phases of operation and test as the various subsystems, and ultimately the image understanding software, are added. However, a general picture can be presented, along with some more information on how it navigates and is programmed. Some of these statements reflect what FERMCO engineers perceive as being necessary rather than specific plans from the SRTC developers.

A Graphical User Interface (GUI) will be provided to allow convenient operation of the robot as well as presentation, interpretation, archiving, and retrieval of its findings. This operating environment will run on the base station computer and may also be accessible from other networked computers through the use of client/server facilities such as those provided by $X$-windows. No particular expertise in either robotics or computer science will be required of SWAMI operators. Menus and graphic icons will be used to make this possible.

Control functions that will be provided will include path specification and modification, diagnostic tools, manual control and full direct access to the HelpMate controller. Daily mission specification may be required for storage areas too large to be covered in a single shift, or to specify particular sets of drums to be inspected. A desirable and feasible feature would be the automatic generation of SWAMI's path points based upon either the database retrieved locations of specified containers or a particular zone of waste storage area. This feature would be particularly useful for storage areas that experience high turnover or frequent reconfigurations.

In the early phases an operator/inspector will be required to view each drum image. Features will be provided to make this as easy as possible. A large color monitor will be required to produce high fidelity images on the screen. Quick response and image display will be critical in achieving user acceptance. zoom and side by side display of two images will also be useful. other operation related features of the base station computer are discussed in section $\mathbf{8 . 2}$, after an introduction to its database access features.

SWAMI's mobility is controlled by two parallel wheels centrally located on the bottom of its HelpMate base. Four idler casters are situated on its corners for stability. By counter-rotating, the drive wheels can cause the robot to turn in place, which is very useful for maneuvering in the cramped aisles of the storage areas. As previously indicated, extended reverse motion is currently not supported. 
Paths for the HelpMate base are specified through AutoCAD generated files that specify a limited number of points at which the robot either dwells or simply passes through. The path points form a series of linear line segments that the robot follows.

As illustrated in figure 15, two other line types can be drawn in order to restrict the maximum deviation from the robot's desired path. Other features could be added to the AutoCAD file, such as the location and height of pallets. One type of line defines areas that the robot should never enter, while the 'force field' line discourages travel across it in proportion to the robot's distance over the line. An application for this type of line would be pedestrian walkways that are navigable but preferably only by people.

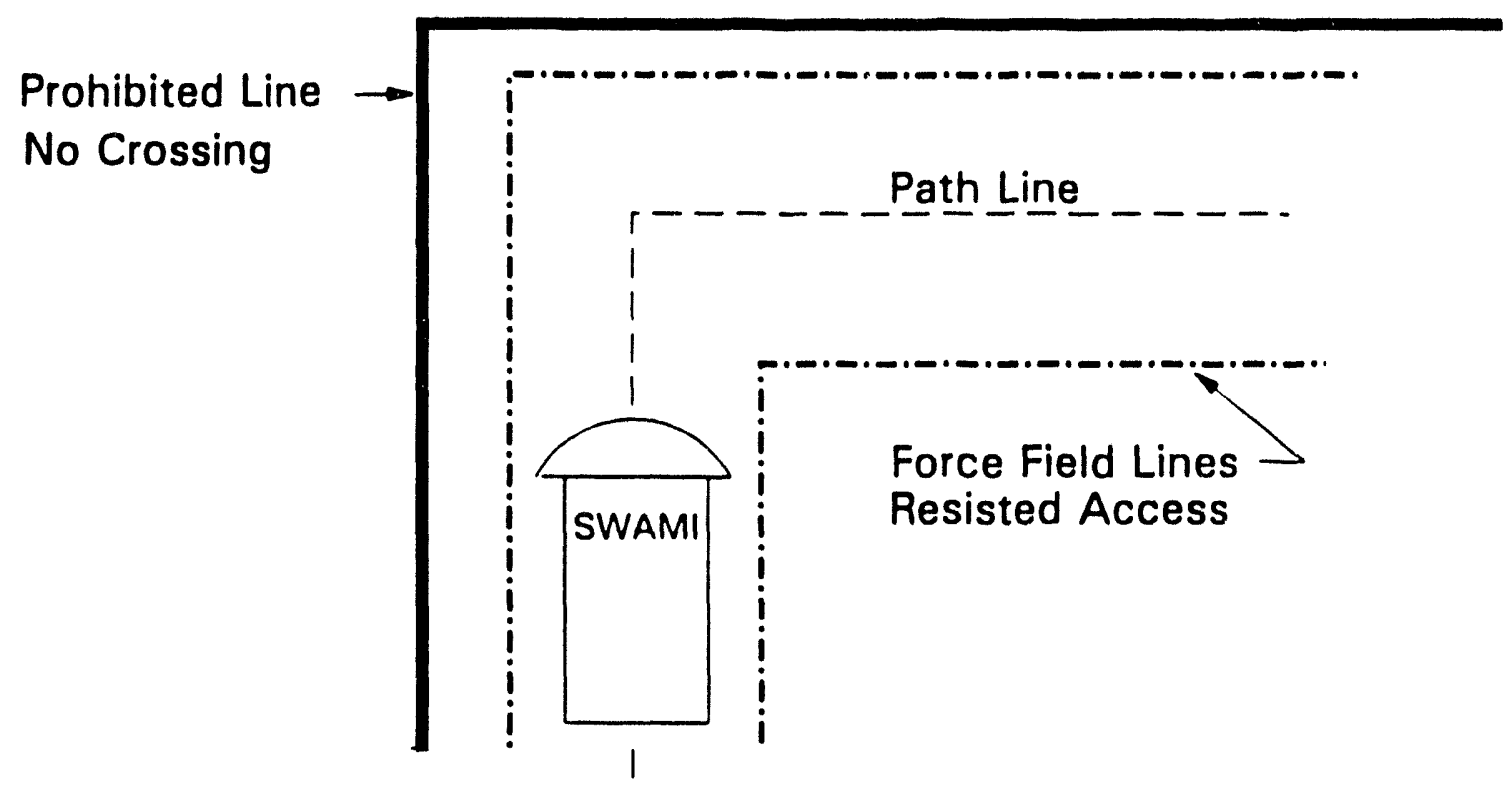

Figure 15- SWAMI path control

Self navigation is a fundamental requirement for mobile robots. It must be done successfully and accurately in order for the robot to operate safely and respect its preprogrammed prohibited zones. The core navigation package developed by TRC mostly relies on 'dead reckoning'. In this method, heading and distance traveled is measured and used to update the robot's internal understanding of where it is. Due to the potential for wheel slip and other anomalies, this internal representation can become inaccurate over significant distances. 
The HelpMate periodically uses its ultrasound sensors to recognize fixed features of the space in which it is traveling. It does this in order to update its position to remain accurate. These features and their exact locations are once again input from AutocAD files. Doorways and the ends of halls can be used for this purpose. The reflective tape sensor previously introduced can also be used to update the robot's position.

A third level of position verification will be available on SWAMI. The hemisphere shaped object on the top of SWAMI (Figure 14) is a NavTech range finder. It is an optics based system that scans the area around the robot for passive beacons placed in fixed, known locations. The beacons consist of several one inch wide strips of reflective tape placed at varied spacings so that multiple beacons can be differentiated.

Once identified, the NavTech system can determine the angle to the beacon accurately. The angle information can then be used to compute position and compared to the dead reckoning value in order to correct it. If the value is incorrect, the robot must travel to several different vantage points and measure its range to the beacon again in order to compute its actual position. If three beacons can be located from a single vantage point, the position can be quickly determined from one location.

\subsection{Fernald site requirements for swakI operation}

Fernald waste storage managers, inspectors, and facility owners have welcomed the opportunity to participate in the field demonstration of the SWAMI robot and have already been active in the project. Various requests for information about the facilities, storage and inspection practices have been and will continue to be readily supplied as requested and required. In fact, Fernald's materials management has expressed hope that the robot will be able to continue its patrols long after the field demonstration is finished.

Demand for space in RCRA and mixed waste storage areas will increase as remediation operations begin in earnest. The turnover in some storage areas will be high due to matched increases in shipping activity. Other materials will be stockpiled if no disposal options are immediately available. This may well happen with mixed waste. The net result will be a growing demand for inspectors so that no presently employed inspector should fear losing their job from the installation of SWAMI. In any event, SWAMI will not be able to perform several of the other important facility inspections that are part of the RCRA regime. 
The following section discusses functional requirements of the system and includes some items that are desirable but may not be possible to implement in the short term. The internal Fermco approval process will be outlined, followed by the types of requirements that must be met in order to insure that high quality systems are used at Fernald.

\subsection{Functional requiroments}

The most important functional requirement will be that the SWAMI system operate safely and effectively, conforming to the operation specifications agreed to and mutually understood by both system developers at SRTC and users at Fernald. The key test that inspectors, regulators, and other observers will apply follows:

Can the SWAMI robot detect suspect drums as well and as reliably as a human inspector can?

As part of the field demonstration, 'John Henry' side by side evaluations of the robot's performance will have to be conducted. Success will lead to greater confidence in its operation and greater dependency upon it in the future. Beyond the visual inspections, other aspects of the system will be immediately useful, including the advanced methods of documenting container condition, inventory verification, and rad surveys of the aisles.

Facilities and environmental requirements were implicitly presented in section 4.1 . It must be able to navigate and operate in building 79 and TS-5 year-round (see Figures 7 and 8 for facility illustrations and dimensions). These buildings will present higher variations in humidity and temperature than HelpMates have previously operated in. The robot must be able to negotiate the ramps over dikes as illustrated in Figure 2 .

Fernald inspection managers place no specific target figure for the number of barrels inspected per day by the unit though the maximum possible coverage is desired. To increase the robot's speed beyond 1 inch per second, the radiation detectors can be turned of $f$ when not required. This could be used to improve the robot's image capture rate, if needed.

As previously presented, ease of use and programming will be important factors affecting its acceptance. System reliability will also be a key concern, as frequent early failures will annoy and discourage those that are trying to learn how to operate it.

SWAMI will not be required to pass between separate rooms or buildings, or open any doors, though these may be beneficial features for other storage areas. Many drums are presently stored outside and, while outside operation is not expected out of the original unit, this might also be a useful addition eventually. 
Several other features would be desirable and feasible modifications to the present sWAMI specifications. One is the inspection of drums stacked on a fourth pallet. These drums, at 13 feet high, are difficult for an inspector to see, especially when the best perspective for viewing the key area of the drum's bottom seam is from above. This would alleviate the difficult and inefficient task of clambering up ladders or high lifts to inspact those containers.

Another desirable feature would be surfaces and enclosures that make it easy to survey and decontaminate SWAMI. While the storage areas are fairly uncontaminated at present (see Figure 9), it is possible that a leaker could spill its contents, or even tumble onto, the SWAMI robot. Also, when transported between facilities, SWAMI will need to be bagged out if it cannot pass a rad survey. Any modifications that serve to better seal the robot and facilitate its decontamination would be useful.

\subsection{Required approvals}

This section will concentrate on inspections and approvals that are required by Fernald for the operation of a new piece of equipment. DOE, NRC, EPA, and OEPA requirements for RCRA inspections and operating equipment were already discussed in section 4.3. Issues relating to acceptance of the use of SWAMI in these RCRA inspections is presented in section 7.0. Quality assurance and control is treated separately in 6.3 .

Key documents that have to be produced include a work plan, test plan, safety assessment, and health and safety plan. Generally they consist of a brief scope of work, introduction to the system, and specific information as required. The work plan subsumes the two other plans mentioned. Many issues raised focus on development of standard procedures for SWAMI's use under normal operating conditions. Fairly limited procedures for its operation during the demonstration will be sufficient at that time and can be used to concurrently develop more comprehensive procedures for its use under normal operating conditions.

The Health and Safety plan is developed through a series of iterations between developers and Fermco's Occupational safety and Health department. There are issues of concern such as industrial hygiene and safety, and radiological control. Industrial hygiene seeks to assure worker safety from physical and chemical hazards. Radiological control protects them from being contaminated. Fire protection has an interest in making sure that SWAMI doesn't cause a fire or otherwise spontaneously combust. 
Safety and risk assessments may also be required as one or two separate documents if the system is perceived as posing a significant threat to the environment or human health. Indications from the responsible departments are that these will not be required. A preliminary safety assessment was requested and will be completed. In addition, a Health and Safety Plan for the sWAMI field at Fernald was also completed in January of 1994.

An initial meeting has already been conducted to start a dialog leading to the acceptance of SWAMI. Representatives of Industrial Safety, Nuclear and system Safety, Fire Protection, Radiological Compliance, as well as materials management and robotics, were invited.

Due to the fact that Fernald has never before had a mobile robot on site, those in attendance were intrigued by its novelty and somewhat unprepared to assess its hazards immediately. They requested that the robotics engineers at Fernald furnish the safety requirements that other sites have applied to similar installations and this will be accomplished shortly.

Concerns that were raised mostly focussed on whether the robot could harm a person if all of the obstacle sensors failed. The slow maximum speed of SWAMI and the location of the emergency mushroom kill switches satisfied those in attendance that this was unlikely. The establishment of a functional diagnostic checkup prior to a night's mission was determined to be a potentially useful feature to assure the robot's continuing safe operation.

The ability of the robot to tip over stacked pallets of drums was also explored. The maximum torque of the drive motors and robot weight need to be determined and furnished to answer this satisfactorily. There was also concern about the tipping hazard that may be presented by SWAMI's tall masts. The center of gravity of the robot should be determined in order to allay this concern. This dialog will be continuing in the coming months and additional concerns and requests for information can be expected.

The use of radio controlled equipment at a Government site is regulated by both the FCC and the DOE. A preliminary report indicated that commercial frequencies were difficult to get approved and the frequency approval for the Government bands, from the Interdepartment Radio Advisory Committee, took months at best. The best way around this roadblock would be to use infrared telemetry or keep the power output below $5 \mathrm{~mW}$. It has since been indicated that wireless Ethernet using spread spectrum, such as is installed on SWAMI, is also acceptable. 


\subsection{Quality assurance and control}

In order to demonstrate SWAMI at the FEMP, the Quality Assurance (QA) department only requires that standard operating procedures be instituted for its operation during the demo, and that the operators be trained properly in adherence to them. If the SWAMI was used more permanently, a greater number of requirements would be placed on the system provider. SRTC, as the developer, would be considered the 'vendor', no matter how much or little money is paid for the system. The following discussion refers to the more stringent requirements of a permanent installation.

Fermco has developed an internal QA standard that they call RM12. By design, it meets these other standards: NQA-1, DOE order 5700.6C, and the EPA's QAMS 005-80. SWAMI will have to adhere to Fermco's quality level \#3, which is applicable for systems that have had moderate modification of off the shelf components. This level reflects the amount of custom engineering involved and not the level of hazard to humans or the environment.

Several criteria have been developed by QA to check the quality of systems used at Fernald. Five of these apply to a permanent SWAMI robot, specifically training, documents \& records, work performance, procurement, and independent assessment.

The first requirement is that a program be established to train SWAMI operators. The training must include instruction in the adherence to the pre-established standard operating procedures. These operating procedures may be developed at the demonstration but must be completed before normal operation can begin.

The training program must insure that operators are capable of normal SWAMI operation and have a basic understanding of its major components. It must include training in how to handle various failure modes and to identify and control any resulting effects. This should include sources of variability in robot performance and the degree to which the operator can or cannot control it. The instruction must be provided by qualified instructors and the training program must be periodically reviewed to insure that it is effective and adjusted as appropriate.

The SWAMI developer must have a program to control the release and revision of documents and records pertaining to the design of the as-built system.

If SWAMI automatically updates some of Fernald's databases as part of its operations, the updates must adhere to additional restrictions. The changes must not obscure the original entry. The changed data must have a record indicating the reason for the change, be flagged as changed, and identify who made the change and when. 
standard operating procedures for the robot must be developed. The procedures must be validated and verified by technically qualified personnel, which, in the case of SWAMI, will include both the SWAMI developers and the waste certification group on site. These procedures must be provided to the operators of SWAMI.A pxocedure to control the calibration, maintenance, and use of SWAMI must be developed. This process can be developed during the demonstration. If possible, these procedures should be traceable to national standards.

$Q A$ is also responsible for assuring the quality of procured systems. They shall implement the appropriate controls to assure the quality of the selection, determination of suitability, evaluation, and receipt of commercial-grade items. The vendor must provide a means of insuring that the parts in SWAMI will work as they are designed to. The vendor must supply a certificate of compliance to "Buy American" and "Suspect parts" requirements. "Buy American" encourages vendors to use U.S. products where available; SWAMI is very compliant in this requirement. The "suspect parts" requirement indicates that parts must not be used or reconditioned and must be up to FERMCO's high standards.

For a permanent emplacement, the QA department may wish to perform supplier audits to insure that they meet the quality requirements of Fernald. They will also evaluate the supplier's QA program for concurrence with quality requirements. The receipt inspection will insure that when it arrives on site it conforms to the established QA/QC criteria. These will be determined through the discussions with SWAMI developers, Fermco robotics, and the $Q A$ procurement officer. QC is not capable of performing in depth inspections of SWAMI's circuits and software. They may, however, perform full functionality checks as well as inspecting for shipping damage.

\subsection{Regulatory approval for BWAMI operation}

SWAMI's main purpose is to inspect containers in a manner that is consistent with the activities and intent proscribed by RCRA regulations. The use of robots like SWAMI to inspect the waste storage areas was not foreseen by the creators of the RCRA statutes, nor by the EPA and OEPA regulators who interpret and enforce RCRA. Hence, it is important to explore what additional regulatory acceptances might be necessary so that both SWAMI and its inspection results are acceptable for RCRA compliance. A proactive stance that results in early dialog with regulators is the best way to insure that swAMI is not only accepted but also welcomed in its inspertion role. 
Fernald will take the lead in establishing this dialog. An early milestone date for submitting proposed sWAMI inspection requirements to the (appropriate) EPA has been set for the end of January 1994 as part of Fernald's Technical Task Plan (TTP) for this activity. This will be only the first step in a process that may be quite time consuming. Fernald's approach will be to first focus on acceptance of the use of SWAMI in the field demonstration before handling the more general issues of its approval for routine daily operations. The technology development group at Fernald has a regulatory expert that will contribute part-time to the efforts of the robotics engineer tasked with obtaining the approval.

The purpose of this activity is to insure that the performance specifications to which mobile container inspection robots such as SWAMI are built will be sufficient to comply with regulatory requirements. The target will be a set of acceptance criteria confirming that a robot that conducts container inspections at a stated level of performance will be sufficient to meet regulatory requirements, at other DOE sites.

Generally, RCRA compliance is monitored by state EPA offices and not by the Federal EPA. Since we desire to obtain blanket approval for the use of the container inspection in any state, approval from federal regulators is desirable and will generally be sufficient for state regulators also. Fernald is covered by Region $V$ of the EPA, with headquarters in Chicago. That field office is known for its stringent regulatory interpretations. The implication is that guidance issued by this regional office will be acceptable by other offices with jurisdiction over the other DOE sites.

In informal discussions with state of ohio EPA, one official indicated that we would probably need to define the performance of the human inspector and then demonstrate that the automated system meets or exceeds the manual performance. We will work closely with materials management personnel to identify all applicable performance measures. These measures will also be of use in the development of the technology and in the creation of data that can be used in cost justification of the system.

Therefore it is probable that a performance demonstration and documentation thereof will be required in order to show that the robot meets the inspection criteria. The approach that will be taken is to establish exactly what the state of ohio and Federal regulators would consider to be sufficient standard operating Procedures. The EPA approved performance specifications would then be used as a checklist to qualify a specific robot at a site in a particular state. It may be possible to schedule an official test of the SWAMI robot for the regulators during the later stages of the SWAMI field demonstration in FY 1995. 
In order to develop this checklist, we will approach both state and Federal regulators to establish the correct channels in order to obtain this guidance. Before this can happen, DOE-FN officials will have to be further apprised of our activities and given a chance to approve our approach. They may also be able to help expedite the process of making the initial contacts.

Regulators may look favorably upon SWAMI because it enhances the established methods for inspection. Being charged with protecting human health and the environment, they may look favorably upon the reduced exposure hazard that SWAMI affords. The improved inspection documentation may also be favored. If container label checking can be added, it will only heighten the attractiveness of SWAMI to the regulators.

While present inspection personnel may be rightfully skeptical, it is very possible that SWAMI will outperform human inspections in diligence and thoroughness- SWAMI never will bore of its job, feel tired, or be distracted. In the most optimistic scenario, regulators may come to adopt sWAMI-type inspections as a requirement for waste facilities because of the ALARA reductions, improved documentation, and potential for improved inspection performance.

Most immediately critical for SWAMI developers, however, is the determination that its field demonstration will be acceptable to the regulators. Hence this will be the only focus at first. Preliminary indications are that this should be readily achievable. Agreement on the guidelines, procedures, and test plans that should be in place so that adequate performance of SWAMI in RCRA compliance can be demonstrated will follow immediately thereafter.

\subsection{Database integration}

SWAMI will be gathering a large amount of data on each night's patrol. Assuming it passes through 2500 feet of aisles with 55 gallon drums stacked 3 pallets high on 4 foot long pallets, 1500 container images could be collected. If the images are compressed to 50 Kbytes, daily storage requirements for the images alone will be 75 Mbytes. Additional storage will be required for the rad survey and inventory verification results.

With so much data being generated, it is important the it be stored in a way that permits convenient and well organized access. Many of SWAMI's benefits will not be fully realized if the reports it produces are not integrated with existing waste material databases at DOE sites. Also, SWAMI will also require information from the database in order to verify inventory records and for other purposes. 
In first subsection, Fernald's new site-wide database is presented. Data connectivity issues between SWAMI and the new database are discussed in the second subsection. Due to the sheer volume of data the SWAMI generates, a separate, off-line storage system may be required, especially if historical records are to be accessible. proposals on how to adequately meet the site's needs will be submitted. Though the presentation will focus on the immediate situation at Fernald, the issues of data connectivity will be encountered at all DOE sites, between other SWAMI's and each site's individual database implementations.

\subsection{Introduction to the 8wIPTs materials database}

The sitewide Waste Information Forecasting and Tracking system (SWIFTS) is a new, user-friendly waste management database that will quickly and accurately obtain all necessary information concerning sitewide wastes. The existing databases are not integrated nor accessible from all on-site users. Redundancy and inconsistency of information have resulted. Bar coded ID's are not yet used as the identification key for many waste containers on site. SWIFTS will encompass and/or supersede all present databases pertaining to waste streams, as well as providing new functionality that allows forecasts of future waste storage, shipment, and treatment requirements.

Databases on site that will be superseded include the All Materials Inventory (AMI), which tracks containerized waste; The Material Evaluation Forms (MEF) which keep tabs on contents and sampling history; And The Material Control and Accountability (MC\&A) database that tracks nuclear materials for reports to the DOE. Figure 16 summarizes this.

SWIFTS will be written in the ORACLE database language and will support client/server relationships between users terminals and the database. It will be available from all-nodes on the site's Ethernet network. It will build upon the previously developed stored Waste Information Tracking system (SWITS) from Hanford.

The use of ORACLE and kinship with Hanford's SWITS database will enhance the portability of any interfaces developed between SWAMI and SWIFTS. ORACLE can call $C$ programs and can be called from $C$ programs, so that SWAMI to SWIFTS integration will be further facilitated.

The main feature of interest to SWAMI developers will be the integration of all information pertinent to a particular container in one record, keyed off of its barcoded ID. Tagging container inspection reports to specific container records is one of the most important links that will occur as SWAMI and SWIFTS are integrated. 


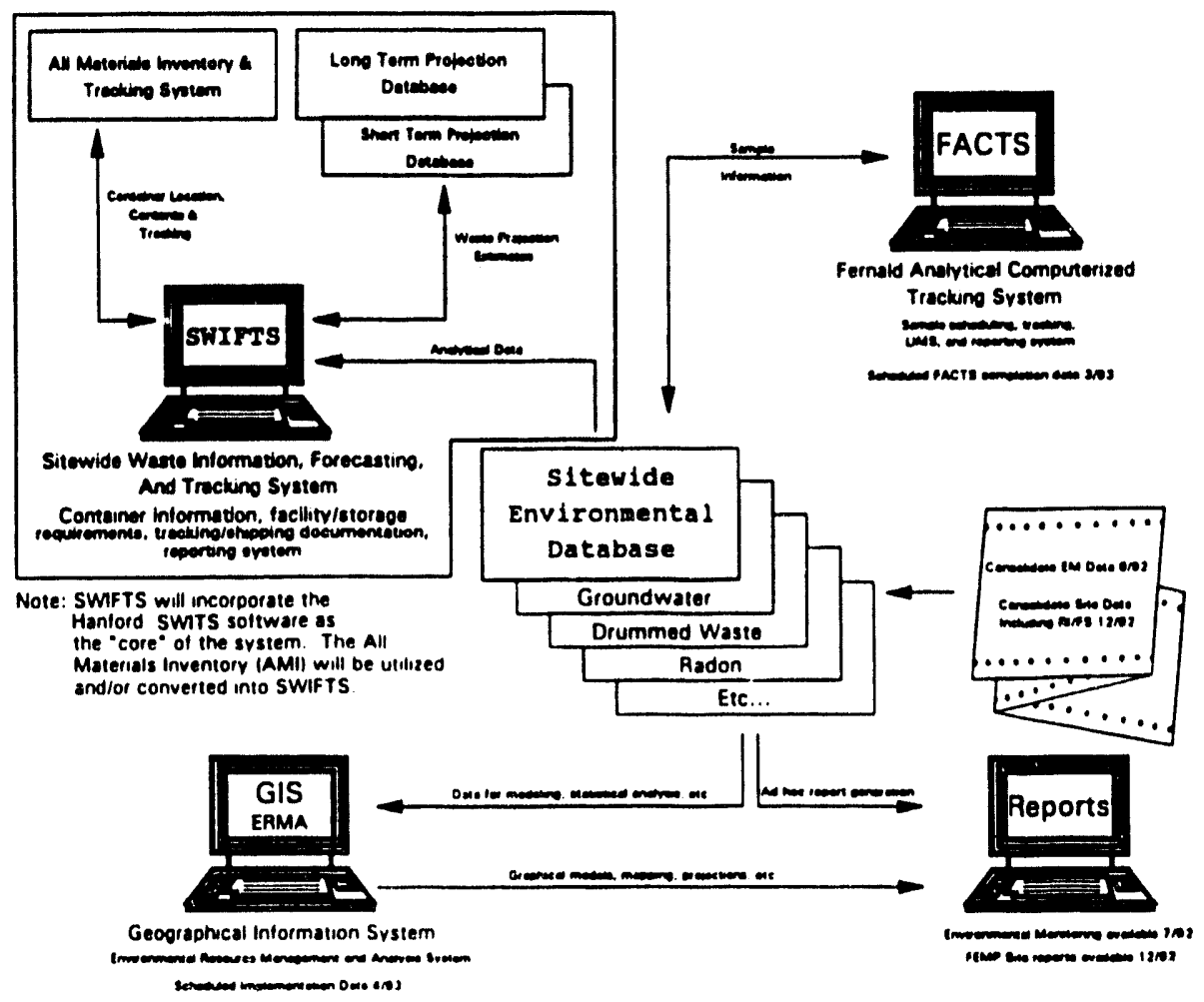

Figure 16- Proposed SWIFTS Integration with existing FEMP databases

A potential benefit of the linkage between the present waste situation and future needs is that all of the static and future information about the various waste streams will be available. A likely future enhancement will be the automated generation of dispatches for many site operations including treatment, sampling, intrasite and offsite shipment and perhaps even container inspection. The implication is that sWAMI may eventually be dispatched on its missions automatically, based upon computer generated requests.

\subsection{Proposed 8WAKI integration}

SWAMI and the SWIFTS database will need to share and transfer information in order to yield the maximum benefit from both systems. The most important data will be the container images and reports on their analysis. Inventory verification will require bidirectional communications. The rad surveys will need to be reported to the radiological safety department as well as facility owners, if suddenly elevated readings are observed (probably due to a leaking container). 
The base station computer will serve as the link between SWAMI and SWIFTS and will run conversion utilities that translate file formats between those two systems. Making additions directly to the SWIFTS database will require that the modifications be validated. Hopefully the system can be tested and qualified so that this can be done automatically and without written approvals or signatures. For the purposes of documentation, data integrity is best guaranteed by writing it to some form of Write Once Read Many (WORM) drive, such as CD-ROM's. However, this would make data transfer a more manual process. These tradeoffs will be explored further before a final decision is made.

In the event that SWIFTS or the network is temporarily unavaijable, the base computer will serve as a data buffer so that operations can continue for a limited amount of time. Several different semiautonomous, periodic processes will have to be developed in order complete the connection between the robot and its database.

While sWIFTs can store image files and other binary data in the LONG RAW format of ORACLE systems, the large number of images would quickly overrun the storage capacity of the SWIFTS system. A more practical solution would be to develop an image identification numbering system, store them on an 'image server' and provide access functions to allow the images to be transmitted across the network to any computer that supports image viewing. The most likely machine for the image server would be the base station computer.

For instance, the Photostyler software package can display SWAMI's JPEG images on PC compatibles running under MS-Windows. In this case, a list of image-ID and date-taken data pairs could be stored more tersely in swIFTs while still allowing the images to be accessible upon demand.

Several 'jukebox' type storage systems are available for the many different types of mass data storage systems that have appeared in recent years. No decision has been made as to the best data storage product at present. Demon processes running on the base station computer could selectively port images to off-line storage as they become progressively older and less likely to be recalled. All of the images and other data collected would always be available offline for at least 3 years, but only recent images would be directly on-line. For instance, one container might have the last four weekly inspection images available on-line, then one each from 3,6 , 12,24 and 36 months past.

Another process running on the base station computer will translate the locations at which SWAMI found specific drums from path coordinates to the format in which those positions are maintained in the SWIFTS database, most likely aisle, row, column, and level. This information will then be compared to the locations stored in the sWIFTS database. At that point, the sWAMI-observed positions could be used to update the database if the procedure is qualified. In either case, an exception report would be generated so that the cause of the discrepancy could be discovered. 
The rad surveys will also need to be translated from path coordinates to physical locations using some periodically activated program. Reports of the suspect drum lists (with images attached), rad surveys, and inventory exceptions will be available daily.

The following discussion highlights additional features that are not presently planned but could be implemented fairly easily after the core functionality has been proven in service.

Should vision based recognition of drum labels be feasible, additional reports will be generated for those drums that were observed to be non-compliant. If material compatibility checking is included, the types of materials in the drums will have to be downloaded before SWAMI heads out for a patrol, lest the unit be forced to have to constantly query the database for the waste types within the drums in order to see which set of labelling rules should be applied to its inspection.

Additional functions may be required of the base computer prior to the inception of a night's patrol. It is likely that container turnover in some storage areas will be very high. since different drum sizes are used, the positioning of the cameras will have to be programmed based upon the stacked height of the drums at different locations of the storage facility. Also, if aisles are filled or cleared during the daytime, SWAMI will have to be informed of this fact so that it does not waste its time and power on nonexistent drums, nor should it miss newly added containers. A fairly sophisticated process running on the base station will eventually be needed to translate the real-time storage facility configuration into a path and action profile for the robot. This process might also be responsible for scheduling inspections in areas too large to be covered in one shift.

The base computer could interact with SWAMI in order to functionally test it prior to a mission. Random container images could be presented to the robot on the computer screen; successful recognition of images of defective drums would qualify it for that evening's service.

\subsection{Conclusions}

This report has presented a comprehensive review of information pertinent to the field demonstration of the SWAMI robot at Fernald. After a background discussion of the Fernald site and its waste inventory, the SWAMI development team and plans were outlined. Waste storage procedures, facilities, inspection criteria and regulations were covered. The SWAMI system was described in detail with particular emphasis placed on its operation and safety features. Fernald site requirements were explicitly outlined in section 6 . The approach that will be taken to obtain regulatory acceptance for the use of the robot, first as a supplement and eventually as a partial replacement to manual inspection, was presented. The swIFTs database with which it will interface with and the way that the two systems will interact was described. 
A SWAMI unit that performs at the level presently specified for the second prototype will be welcomed as a vast improvement especially in the area of documentation and inventory verification. Additional features that could be added later to further improve SWAMI have been identified in the course of the site requirements investigation. These include the inspection of fourth level drums, decontaminability, functional self-testing, inspection for proper label placement, and self-reprogrammability based upon real time storage area configuration.

The SWAMI development project will result in a new method of inspection with broad applicability within the DOE complex, and potentially for industrial waste generators as well. The full benefits of SWAMI will not be realized if it does not address the specific needs of the sites that use it.

In the case of Fernald, the most critical need is for the unit to reliably function as advertised and to connect seamlessly with the databases that can effectively manage the large volume of data that SWAMI will generate. While Fernald cannot speak for all DOE sites, it is probable that its requirements will closely follow those of other DOE facilities, especially in the manner in which the waste is stored, the reporting requirements that drive the need for the system, and in the type of database with which it must be integrated. SWAMI developers and initial users now have an excellent opportunity to advance the state of the art in materials management and robotics, to the mutual benefit of both parties.

\subsection{Contacts listing}

This list is intended to provide a directory of organizations that are involved in one of the three container inspection robotics projects funded by the DOE. Phone numbers have been deliberately omitted; kindly send requests for information by mail.

Immediate questions or comments on the report should be forwarded to Mr. Hazen of Fermco: His phone number is listed below.

Savannah River Technology Center - SWAMI Developers

Mr. Clyde Ward, MWO coordinator/SWAMI Principal Investigator

Mr. Kurt Peterson, SWAMI project lead

(Fax) 803-725-5891 Westinghouse Savannah River Company

Building 773-A, D-1134

Aiken, SC 29808 
Fermco- Field demonstration site

Mr. F. Brack Hazen, Senior robotics engineer (roport author)

MS 81-2 (Ph) 513-648-6554 (Fax) 513-648-6915

Mr. John Eckstein, manager of waste facilities

FERMCO

PO BOX 45239-8704

Cincinnati $\mathrm{OH}$ 45239-8704

Georgia Tech- SWAMI vision processing and navigation

Dr. Wayne Book

Department of Mechanical Engineering

Dr. Ron Arkin

College of Computing

Dr. Tom Collins

Computer Architecture Laboratory

School of Electrical Engineering

Georgia Institute of Technology

Atlanta Georgia 30332

Martin Marietta Astronautics- PRDA Team 1 , SWAMI vision processing

Mr. Eric Byler

Martin Marietta Corporation

Astronautics Group

P.O. Box 179

Denver CO 80201

Clemson University/University of South Carolina-sCUREF PRDA Team \#2

Dr. Fred Sias

Dr. Bob Schalkoff

Department of Electrical and Computer Engineering

Clemson University

Clemson, S.C. 29634-0915

Dr. Joe Byrd

Department of Electrical Engineering

University of South Carolina

Columbia, S.C. 29208 


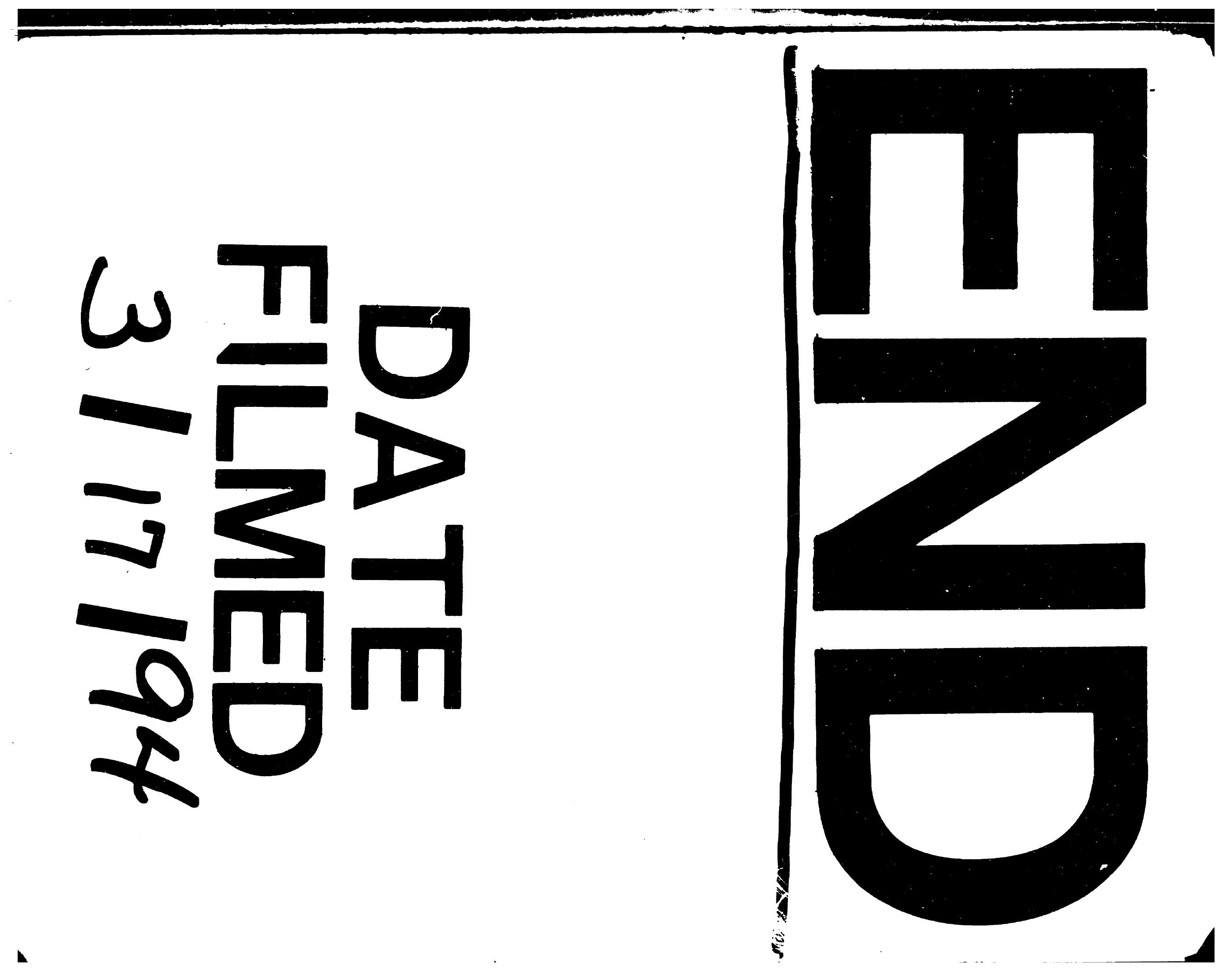



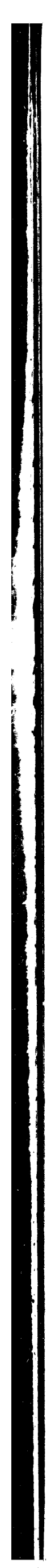